
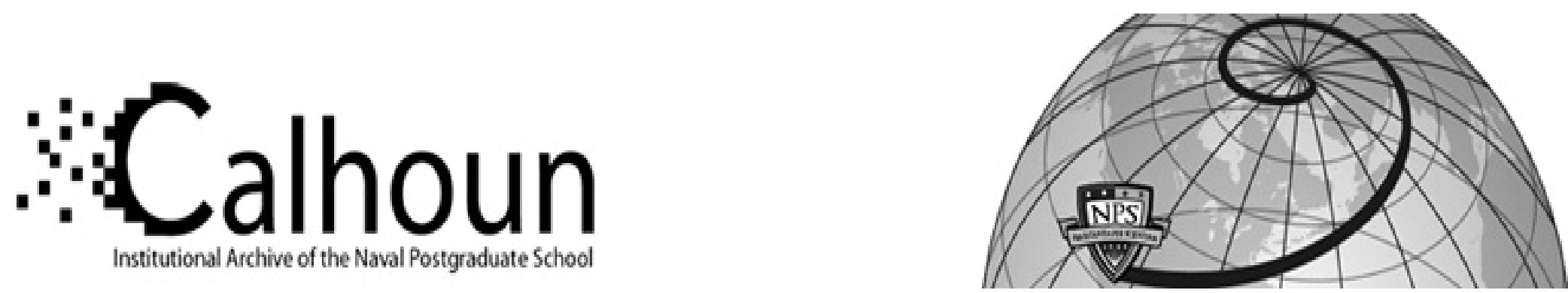

Calhoun: The NPS Institutional Archive DSpace Repository

A Composite Perspective of the Extratropical Flow Response to Recurving Western North Pacific Tropical Cyclones

Archambault, Heather M.; Keyser, Daniel; Bosart, Lance F.; Davis, Christopher A.; Cordeira, Jason M.

This publication is a work of the U.S. Government as defined in Title 17, United States Code, Section 101. Copyright protection is not available for this work in the United States.

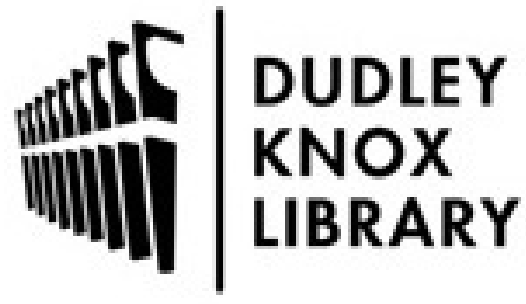

http://www.nps.edu/library
Calhoun is the Naval Postgraduate School's public access digital repository for research materials and institutional publications created by the NPS community. Calhoun is named for Professor of Mathematics Guy K. Calhoun, NPS's first appointed -- and published -- scholarly author.

Dudley Knox Library / Naval Postgraduate School 411 Dyer Road / 1 University Circle Monterey, California USA 93943 


\title{
A Composite Perspective of the Extratropical Flow Response to Recurving Western North Pacific Tropical Cyclones
}

\author{
HeAther M. ARchambaulT* \\ Department of Meteorology, Naval Postgraduate School, Monterey, California \\ DANIEL KeYSER AND LANCE F. BosarT \\ Department of Atmospheric and Environmental Sciences, University at Albany, State \\ University of New York, Albany, New York \\ CHRISTOPHER A. DAVIS \\ National Center for Atmospheric Research, Boulder, Colorado \\ JASON M. CORDEIRA \\ Department of Atmospheric Science and Chemistry, Plymouth State University, Plymouth, New Hampshire
}

(Manuscript received 22 August 2014, in final form 18 December 2014)

\begin{abstract}
This study investigates the composite extratropical flow response to recurving western North Pacific tropical cyclones (WNP TCs), and the dependence of this response on the strength of the TC-extratropical flow interaction as defined by the negative potential vorticity advection (PV) by the irrotational wind associated with the TC. The $2.5^{\circ} \mathrm{NCEP}-\mathrm{NCAR}$ reanalysis is used to construct composite analyses of all 1979-2009 recurving WNP TCs and of subsets that undergo strong and weak TC-extratropical flow interactions.

Findings indicate that recurving WNP TCs are associated with the amplification of a preexisting Rossby wave train (RWT) that disperses downstream and modifies the large-scale flow pattern over North America. This RWT affects approximately $240^{\circ}$ of longitude and persists for approximately 10 days. Recurving TCs associated with strong TC-extratropical flow interactions are associated with a stronger extratropical flow response than those associated with weak TC-extratropical flow interactions. Compared with weak interactions, strong interactions feature a more distinct upstream trough, stronger and broader divergent outflow associated with stronger midlevel frontogenesis and forcing for ascent over and northeast of the TC, and stronger upper-level PV frontogenesis that promotes more pronounced jet streak intensification. During strong interactions, divergent outflow helps anchor and amplify a downstream ridge, thereby amplifying a preexisting RWT from Asia that disperses downstream to North America. In contrast, during weak interactions, divergent outflow weakly amplifies a downstream ridge, such that a RWT briefly amplifies in situ before dissipating over the western-central North Pacific.
\end{abstract}

\section{Introduction}

Tropical cyclones (TCs) undergoing extratropical transition (ET), a change from a warm-core, axisymmetric

\footnotetext{
* Current affiliation: NOAA/OAR Climate Program Office, Modeling, Analysis, Predictions and Projections Program, Silver Spring, Maryland.

Corresponding author address: Heather M. Archambault, 1315 East-West Hwy., Silver Spring, MD 20910.

E-mail: heather.archambault@noaa.gov
}

system to a cold-core, asymmetric system (e.g., Klein et al. 2000; Jones et al. 2003; Harr and Archambault 2015), may significantly perturb their environment as they recurve into the midlatitudes (e.g., McTaggart-Cowan et al. 2007; Harr and Dea 2009; Cordeira and Bosart 2010). The poleward and upward transport of low potential vorticity (PV) air associated with TC recurvature tends to amplify a ridge and intensify a jet streak along the meridional PV gradient marking the jet stream (e.g., Agustí-Panareda et al. 2004,

Publisher's Note: This article was revised on 10 June 2015 in order to include an updated acknowledgements section. 
2005; Riemer et al. 2008; Riemer and Jones 2010; Cordeira 2011; Grams et al. 2013a; Archambault et al. 2013).

Ridge amplification and jet streak intensification are enhanced by diabatic heating associated with the recurving TC (e.g., Atallah and Bosart 2003) and attendant frontogenesis in its northeast quadrant (e.g., Torn 2010). Above the level of maximum diabatic heating associated with clouds and precipitation, $\mathrm{PV}$ is reduced in conjunction with diabatic vertical redistribution. In addition, the divergent outflow generated by diabatic heating advects low PV toward the PV gradient/jet stream (Archambault et al. 2013, their Fig. 4).

Given a strong, continuous meridional PV gradient (i.e., waveguide; Martius et al. 2010), ridge amplification and jet streak intensification will excite or amplify a baroclinic Rossby wave train (RWT) that disperses eddy kinetic energy downstream while initiating surface cyclogenesis downstream (e.g., Riemer et al. 2008; Harr and Dea 2009; Keller et al. 2014). Thus, a recurving TC may indirectly reconfigure the extratropical flow pattern and influence the sensible weather thousands of kilometers downstream within a few days (e.g., Archambault et al. 2013, their Fig. 1).

On average, the North Pacific flow pattern becomes significantly amplified for approximately four days following western North Pacific (WNP) TC recurvature (Archambault et al. 2013). However, the extratropical flow response to TC recurvature may range from a marked flow amplification [e.g., with TC Oscar (1995); Archambault et al. (2013), their Fig. 1; Harr and Archambault (2014)], to a strengthened jet stream without substantial flow amplification [e.g., with TC Jangmi (2008); Grams et al. (2013a,b)], to little change in the flow pattern [e.g., with TC Opal (1997); Harr and Elsberry (2000)]. Anticipating the extratropical flow response to TC recurvature is crucial given that flow amplification downstream of a recurving TC may induce extreme weather (e.g., Cordeira and Bosart 2010; Grams et al. 2011; Chaboureau et al. 2012; Pantillon et al. 2014) and contribute to reduced midlatitude predictability (e.g., Harr et al. 2008; Anwender et al. 2008; Reynolds et al. 2009; Keller et al. 2011; Pantillon et al. 2013, 2014; Harr and Archambault 2015).

The primary factors influencing the downstream flow response to TC recurvature are (i) the large-scale flow pattern into which the TC is moving (e.g., Harr and Dea 2009; Riemer et al. 2008; Riemer and Jones 2010, 2014), and (ii) the interaction between the TC and an extratropical disturbance such as a trough or jet streak (e.g., Klein et al. 2002; Ritchie and Elsberry 2007; Riemer and Jones 2010, 2014; Grams et al. 2013b; Keller et al. 2014). Characteristics of the recurving TC, such as size and intensity, are thought to be secondary factors (e.g., Harr and Dea 2009; Archambault et al. 2013).
The large-scale extratropical flow pattern into which a TC recurves varies by time of year and by ocean basin. Compared with August-November, June and July are relatively unfavorable for the North Pacific flow pattern to become significantly amplified following WNP TC recurvature (Archambault et al. 2013, their Fig. 15), consistent with the tendency for the North Pacific waveguide/ jet stream to be relatively weak in June and July compared with August-November. A compositing study by Quinting and Jones (2014) indicates that, whereas RWT activity is significantly above average following WNP TC recurvature, it is not significantly above average following North Atlantic TC recurvature. Based on case studies (e.g., Grams et al. 2011; Pantillon et al. 2013, 2014), anticyclonic Rossby wave breaking instead of Rossby wave dispersion may be more typical following North Atlantic TC recurvature, perhaps owing to the climatologically short and weak waveguide/jet stream over the North Atlantic compared with over the North Pacific.

The large-scale extratropical flow response to TC recurvature also depends on the interaction of the TC with disturbances in the extratropical flow. The TCextratropical flow interaction, or phasing, can be considered favorable or unfavorable. An example of an unfavorable phasing between the TC and extratropical flow is the recurvature of WNP TC Jangmi (2008). As the TC recurved into the base of a WNP trough, the jet stream was enhanced downstream but Rossby wave amplification and dispersion did not occur (Grams et al. 2013a,b). Through numerical modeling experiments, Grams et al. (2013a) demonstrate that had TC Jangmi recurved ahead of the trough rather than into the base of the trough, a high-amplitude RWT likely would have been induced. They find that the shift in TC position required to discriminate between RWT and no-RWT scenarios is only $130 \mathrm{~km}$, which they note is the average 48-h TC position error for ensemble mean ECMWF forecasts (Lang et al. 2012).

In a recent climatological study (Archambault et al. 2013), the top quintile of TC-extratropical interactions, defined by the magnitude of negative PV advection by the irrotational wind associated with the recurving TC, is found to be associated with a sustained, highly statistically significant amplification of the North Pacific flow. In contrast, the bottom quintile of TC-extratropical flow interactions is found to be associated with a shorterlived, less statistically significant amplification of the North Pacific flow. In the present study, the climatological study of Archambault et al. (2013) is used as the basis for a comprehensive composite analysis of the extratropical flow response to WNP TC recurvature. In particular, key synoptic-dynamic differences are illustrated between strong and weak TC-extratropical flow 
interactions, which are important to understanding differences in the downstream extratropical flow response to $\mathrm{TC}$ recurvature.

The remainder of this paper is organized as follows. Section 2 describes the methodology. Section 3 presents composite analyses of the midlatitude flow response to recurving WNP TCs and compares composite analyses of strong and weak TC-extratropical flow interactions during WNP TC recurvature. Section 4 provides a discussion, and section 5 contains a summary and an overview of future work.

\section{Methodology}

\section{a. Recurvature-relative compositing methodology}

To examine the extratropical flow response to recurving WNP TCs, all 292 recurving WNP TCs identified during 1979-2009 from the Japan Meteorological Agency best track dataset by Archambault et al. (2013) are composited. Tropical cyclone recurvature is defined following Archambault et al. (2013) as a change in TC heading from westward to eastward as a TC moves poleward. The recurvature point corresponds to the most westward position of the recurving TC. All recurving TCs are required to be at tropical storm intensity or greater at the time of recurvature (i.e., $T+0 \mathrm{~h}$ ), and to eventually become extratropical (i.e., complete ET). The recurving TCs mainly occur during May-December, with a peak in activity during August-October. September has the highest incidence of TC recurvature of any month, with 82 cases identified in 31 years, a frequency of $2.6 \mathrm{yr}^{-1}$.

Composite analyses of the recurving WNP TCs are constructed in a recurvature-relative framework. That is, fields for each case are shifted such that the recurvature point is collocated with the mean recurvature point at the time of recurvature $(T+0 \mathrm{~h})$. As illustrated by a comparison of conventional geography-relative and recurvaturerelative TC tracks (Figs. 1a,b), the recurvature-relative framework reduces composite smearing that would arise from the spatial variability of the recurving TC tracks (Fig. 1a). The track variability partially reflects the influence of the time of year: Between May and August, TC recurvature shifts poleward as the North Pacific jet stream weakens and shifts poleward, and thereafter shifts equatorward through December as the jet stream strengthens and shifts equatorward (e.g., Archambault et al. 2013, section $3 \mathrm{e}$ ).

The 6-hourly $2.5^{\circ}$ NCEP-NCAR reanalysis fields (Kalnay et al. 1996; Kistler et al. 2001) are used to construct the composite analyses. Although higher-resolution reanalyses such as the $0.5^{\circ}$ Climate Forecast System Reanalysis (Saha et al. 2010) are available, the NCEP-NCAR reanalysis is used for consistency with the Archambault

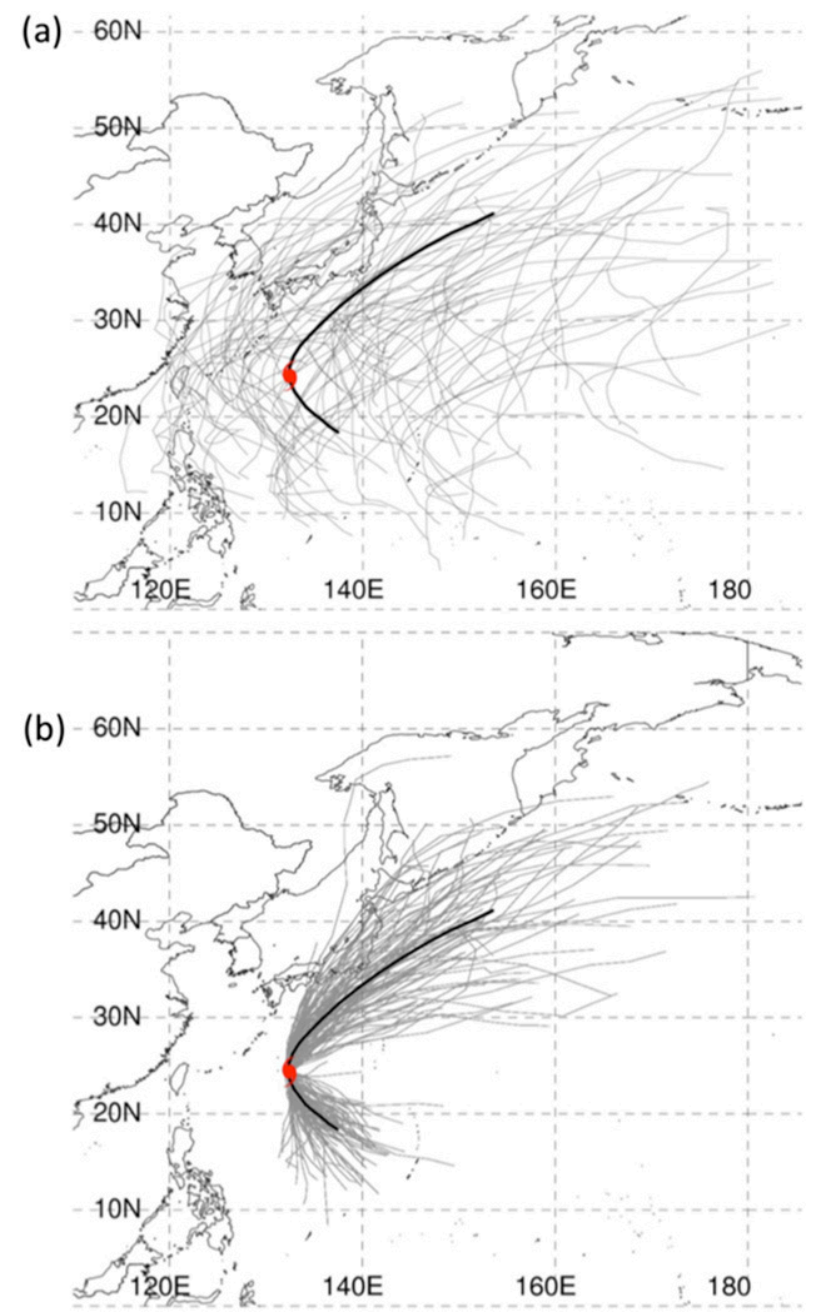

FIG. 1. Recurving WNP TC tracks (2000-09 only; $N=101)$ for $T-$ 48 to $T+72 \mathrm{~h}$ plotted in (a) geography-relative and (b) recurvaturerelative frameworks. The thick black curve denotes the composite track of all recurving TCs $(N=292)$ for $T-48$ to $T+72 \mathrm{~h}$. The TC symbol denotes the composite recurvature point $\left(24.9^{\circ} \mathrm{N}, 134.0^{\circ} \mathrm{E}\right)$ for all recurving TCs.

et al. (2013) climatology. As discussed in Archambault et al. (2013, their section $2 \mathrm{~d}$ ), the $2.5^{\circ}$ NCEP-NCAR reanalysis is able to capture synoptic signatures of TCextratropical flow interactions.

The statistical significance of the composite fields with respect to climatology is assessed using a two-sided Student's $t$ test (e.g., Wilks 2006, see section 5.2.1). The climatology is produced from 1979-2009 21-day running means of recurvature-relative $2.5^{\circ}$ NCEPNCAR reanalysis fields.

\section{b. Interaction-relative compositing methodology}

Composite analysis is used to compare the extratropical flow response to strong and weak TC-extratropical 
flow interactions during WNP TC recurvature. For each recurving $\mathrm{TC}$, the strength of the interaction (i.e., the interaction metric) is defined as the magnitude of the spatially and temporally averaged $250-150-\mathrm{hPa}$ layeraveraged PV advection by the irrotational wind associated with the TC computed from 6-hourly $2.5^{\circ} \mathrm{NCEP}-$ NCAR reanalysis (Archambault et al. 2013, their section $2 \mathrm{~d})$. The spatial $\left(15^{\circ} \times 15^{\circ}\right)$ and temporal $(48 \mathrm{~h})$ averaging is centered on the point and time (i.e., $T+0 \mathrm{~h}$ ), respectively, of maximum interaction, which is defined as the highest instantaneous magnitude of negative PV advection by the irrotational wind associated with the TC. As noted by Archambault et al. (2013, their Fig. 5a) for the case of WNP TC Oscar (1995) and by Cordeira (2011, p. 111) for the case of WNP TC Dale (1996), the region of strongest negative PV advection by the irrotational wind generally tends to be closely aligned with the upstream edge of the TC cirrus shield. A point of maximum interaction is not identified for 20 of the 292 recurving TC cases because the negative PV advection by the irrotational wind associated with the TC never exceeds an arbitrary threshold of $1 \mathrm{PVU}$ day ${ }^{-1}\left(1 \mathrm{PVU}=10^{6} \mathrm{~K} \mathrm{~kg}^{-1} \mathrm{~m}^{2} \mathrm{~s}^{-1}\right)$. These cases are considered no-interaction cases. For the remaining 272 recurving TC cases, those associated with an interaction metric in the top quintile are categorized as strong interactions $(N=54)$, whereas those associated with an interaction in the bottom quintile are categorized as weak interactions $(N=54)$.

As discussed in Archambault et al. (2013, their section 2d), the negative PV advection by the irrotational wind is useful for diagnosing the strength of the TC-extratropical flow interaction because divergent outflow impinging upon the PV waveguide/jet stream is a key signature of Rossby wave amplification induced by a TC (e.g., Harr et al. 2008; Riemer et al. 2008; Hodyss and Hendricks 2010; Pantillon et al. 2013, 2014; Grams et al. 2013a,b). Ridge amplification and jet streak intensification occur in conjunction with Rossby wave amplification as the divergent outflow of the TC deforms PV contours poleward and strengthens the PV gradient (Archambault et al. 2013, their Fig. 4). The effects of diabatic heating are included in this framework, as upper-level low-PV air that arises from diabatic heating is advected by diabatically driven divergent outflow toward the waveguide/jet stream.

To examine strong and weak TC-extratropical flow interactions, composites are constructed such that they are centered on the point of maximum TC-extratropical flow interaction. This "interaction-relative" framework is used to maximize the sharpness of the composite synoptic features associated with the TC-extratropical flow interactions. To construct these composites, the $2.5^{\circ}$ NCEP-NCAR fields for a given case are shifted such that the point of maximum TC-extratropical flow interaction is collocated with the mean point of maximum interaction (Fig. 2). The statistical significance of the composite fields with respect to climatology is evaluated using a two-sided Student's $t$ test. The climatology is produced from 1979-2009 21-day running means of interactive-relative $2.5^{\circ} \mathrm{NCEP}-\mathrm{NCAR}$ reanalysis fields.

For all WNP TCs undergoing recurvature, the point of maximum interaction tends to be located approximately $6^{\circ}-14^{\circ} \mathrm{N}$ of the TC center (Fig. 2). However, for strong interaction cases the location of the mean point of maximum interaction is significantly farther northward $\left(11.6^{\circ}\right.$ vs $8.1^{\circ}$ latitude) and westward $\left(-1.1^{\circ}\right.$ vs $1.5^{\circ}$ longitude) relative to the TC compared with weak interaction cases (Fig. 2; Table 1).

The synoptic signatures and dynamics of strong and weak TC-extratropical flow interactions are compared using a variety of plan-view composite analyses produced at the time of maximum interaction (i.e., $T+0 \mathrm{~h}$ ). The irrotational and nondivergent wind fields are computed for each individual case prior to compositing. All derived variables, including PV advection, $\mathbf{Q}$ vectors, and $\mathbf{Q}$-vector divergence (described subsequently in section $2 \mathrm{~d}$ ), and $\mathrm{PV}$ frontogenesis ${ }^{1}$ [i.e., the rate of change of the magnitude of the horizontal PV gradient; e.g., Davies and Rossa (1998), Cordeira (2011, p. 105)], are computed on isobaric levels from the composite fields.

\section{c. Assessment of characteristic magnitudes of various quantities for composite cases}

Although useful for identifying common synoptic features, composite analyses have limited utility in determining the characteristic magnitudes of these features (e.g., Archambault et al. 2008). To compensate for this limitation, the maximum values of various quantities for the individual cases that constitute the composites are analyzed for strong and weak TC-extratropical flow interactions. For each case, the maximum magnitude of a given quantity in the NCEP-NCAR reanalysis is obtained by searching within a $20^{\circ}$ latitude $\times 20^{\circ}$ longitude box centered on the point of maximum interaction. Whether the mean of the maximum magnitude of a given quantity is significantly different for strong versus weak interactions is tested using a nonparametric two-sided Wilcoxon-Mann-Whitney rank-sum test (e.g., Wilks 2006, section 5.3.1).

\footnotetext{
${ }^{1}$ The PV frontogenesis is calculated by replacing potential temperature with PV in the simplified 2D form of the Miller (1948) frontogenesis equation [e.g., Novak et al. 2004, their Eq. (1)].
} 


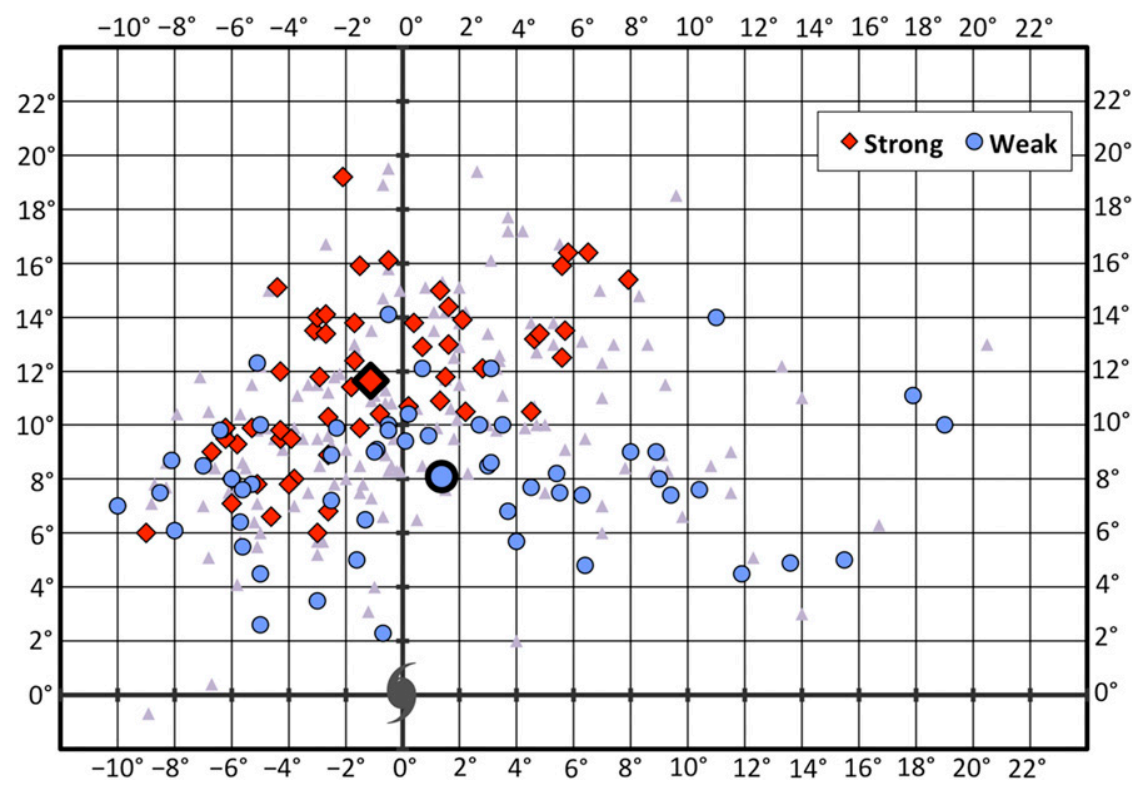

FIG. 2. Points of maximum TC-extratropical flow interaction plotted relative to the recurving WNP TC at the time of maximum interaction for strong TC-extratropical flow interactions (red diamonds; $N=54$ ), weak TC-extratropical flow interactions (blue circles; $N=54$ ), and interactions classified as neither strong nor weak (purple triangles; $N=164$ ). The large diamond and circle represent the mean points of maximum TC-extratropical flow interaction for strong and weak interactions, respectively.

\section{d. Q-vector computation}

To assess regions of frontogenesis and forcing for vertical motion associated with recurving WNP TCs, 700-hPa $\mathbf{Q}$ vectors and $\mathbf{Q}$-vector divergence, respectively, are computed in pressure coordinates following Hoskins and Pedder (1980), except that the nondivergent wind is used instead of the geostrophic wind. In this formulation, the $\mathbf{Q}$ vector describes the time rate of change of the vector horizontal potential temperature gradient due to the nondivergent wind. The convergence of $\mathbf{Q}$ vectors corresponds to forcing for ascent, and the divergence of $\mathbf{Q}$ vectors corresponds to forcing for descent.

The nondivergent wind is used instead of the geostrophic wind to compute $\mathbf{Q}$ vectors because it better represents the balanced wind in curved flow and is better suited for the subtropics where geopotential height gradients are weak and the Coriolis parameter is small. The $\mathbf{Q}$ vector is formulated in terms of the nondivergent wind by Riemer et al. (2014), who employ the framework of alternative balance (Davies-Jones 1991) to examine forcing for vertical motion associated with cyclone development downstream of recurving TCs. In addition, the nondivergent wind is used to compute $\mathbf{Q}$ vectors in studies of North Atlantic tropical disturbances (McTaggart-Cowan et al. 2008), North Pacific subtropical gyres (Molinari and Vollaro 2012), and Northeast U.S. snowbands in winter storms (Kenyon 2014).
To separate the temporal rates of change of the direction and magnitude of the horizontal potential temperature gradient, natural-coordinate partitioning of the $\mathbf{Q}$ vector is performed following the methodology of Keyser et al. (1988, 1992). The unit vector $\mathbf{n}$ is defined locally based on the potential temperature gradient such that at a point $\mathbf{n}$ is directed normal to an isentrope toward lower potential temperature. The unit vector $\mathbf{s}$ is then defined as orthogonal to $\mathbf{n}$ such that $\mathbf{s}$ is tangent to the isentrope with lower potential temperature on the left. The unit vectors $\mathbf{s}$ and $\mathbf{n}$ define a natural coordinate system $(s, n)$ within which the $\mathbf{Q}$ vector is partitioned into along- and acrossisentropic components $\left(\mathbf{Q}_{s}\right.$ and $\mathbf{Q}_{n}$, respectively, where $\mathbf{Q}_{s}=Q_{s} \mathbf{s}$ and $\left.\mathbf{Q}_{n}=Q_{n} \mathbf{n}\right)$.

TABLE 1. The means and standard deviations of the latitudinal and longitudinal distance of the maximum TC-extratropical flow interaction point from the recurving WNP TC at the time of maximum interaction for strong $(N=54)$ and weak $(N=54)$ interactions, and the differences between the means of the strong and weak interactions (degrees). The confidence levels for the significance of the differences based on a two-sided Student's $t$ test are given in parentheses.

\begin{tabular}{ccc}
\hline \hline Strong & Weak & $\begin{array}{c}\text { Difference } \\
\text { (confidence level) }\end{array}$ \\
\hline $11.6^{\circ} \pm 3.1^{\circ}$ lat & $8.1^{\circ} \pm 2.6^{\circ}$ lat & $+3.5^{\circ}$ lat $(99.9 \%)$ \\
$-1.1^{\circ} \pm 4.0^{\circ}$ lon & $1.5^{\circ}+7.0^{\circ}$ lon & $-2.6^{\circ}$ lon $(97.8 \%)$ \\
\hline
\end{tabular}


The scalar quantity $Q_{s}$ quantifies the rate of rotation of the potential temperature gradient by the nondivergent wind such that $Q_{s}>0\left(\mathbf{Q}_{s}\right.$ oriented with higher potential temperature to the right) corresponds to counterclockwise rotation and $Q_{s}<0\left(\mathbf{Q}_{s}\right.$ oriented with lower potential temperature to the right) corresponds to clockwise rotation. The scalar quantity $Q_{n}$ quantifies the rate of change of the magnitude of the horizontal potential temperature gradient by the nondivergent wind. In this framework, $Q_{n}<0$ ( $\mathbf{Q}_{n}$ directed toward warm air) indicates frontogenesis and $Q_{n}>0\left(\mathbf{Q}_{n}\right.$ directed toward cold air) indicates frontolysis.

The divergences of $\mathbf{Q}_{s}$ and of $\mathbf{Q}_{n}$ are also calculated to evaluate along- and across-isentropic forcing, respectively, for vertical motion. In a mature extratropical cyclone, the divergence of $\mathbf{Q}_{s}$ typically exhibits a dipole pattern, whereas the divergence of $\mathbf{Q}_{n}$ exhibits a banded pattern (e.g., Keyser et al. 1992; Martin 2006).

\section{Results}

\section{a. Extratropical flow response to recurving TCs}

Recurvature-relative composite analyses of the upperlevel flow for all 1979-2009 recurving WNP TCs are displayed for $T-72$ to $T+144 \mathrm{~h}$ relative to recurvature time at 36-h intervals (Fig. 3). Potential vorticity and meridional wind anomaly fields are displayed at the 250-hPa level because this level best captures RWT activity associated with recurving WNP TCs. At $T-72 \mathrm{~h}$ (Fig. 3a), alternating positive and negative meridional wind anomalies extend across Europe and Asia. These meridional wind anomalies constitute two low-amplitude RWTs within northern and southern PV waveguides, respectively. The waveguides are most clearly separated from each other at $60^{\circ}-120^{\circ} \mathrm{E}$, near the Tibetan Plateau. The signature of two RWTs in the composite may in part reflect separately occurring northern- and southern-track RWTs accompanying the summer-early fall and spring and late fall cases, respectively.

By $T-36$ h (Fig. 3b), the two RWTs appear to merge over eastern Asia. At this time, the TC is moving poleward toward the region between the leading ridge of the RWT and the adjacent upstream trough. By $T+0 \mathrm{~h}$ (Fig. 3c), the individual Rossby waves constituting the RWT have amplified as the recurving TC begins to merge with the western flank of the ridge. At $T+36 \mathrm{~h}$ (Fig. 3d), the Rossby waves have further amplified, and the RWT now extends across the entire North Pacific.

Between $T+36$ and $T+144 \mathrm{~h}$ (Figs. 3d-g), the RWT disperses across the North Pacific and alters the flow pattern over North America. A ridge is established by $T+72 \mathrm{~h}$ over the eastern North Pacific (Fig. 3e). Thirtysix hours later, at $T+108 \mathrm{~h}$ (Fig. 3f), a positively tilted

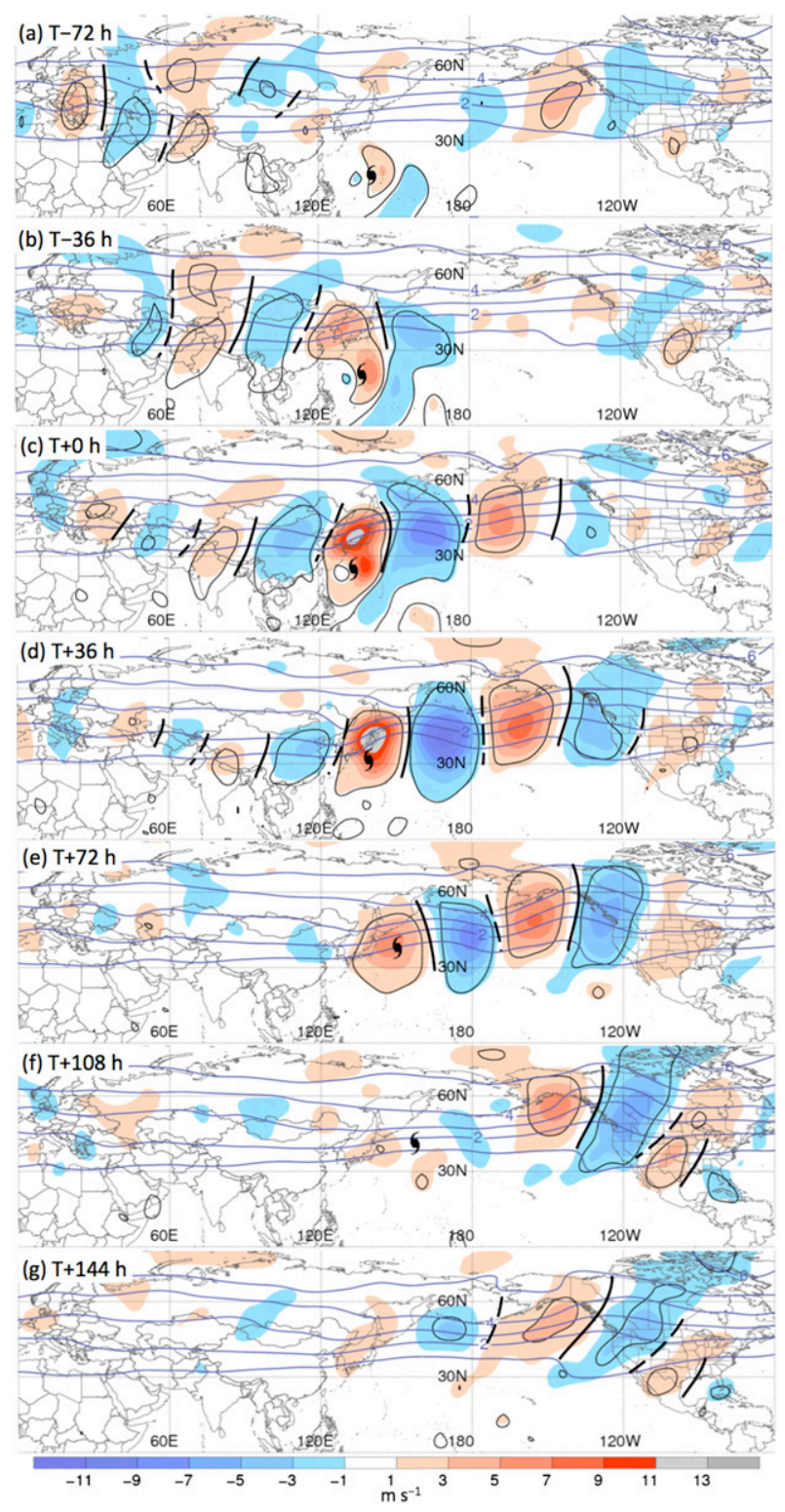

FIG. 3. Recurvature-relative composite analyses of all recurving WNP TCs $(N=292)$ at 36-h intervals for (a)-(g) $T-72$ to $T+144 \mathrm{~h}$. Analyses show $250-\mathrm{hPa}$ meridional wind anomalies (shaded according to the color bar, $\mathrm{m} \mathrm{s}^{-1}$; enclosed by black contours where significant at the $99 \%$ confidence level) and PV (blue, every 1 PVU). The TC symbol denotes the composite TC position, which is plotted for (a)-(f) $T-72$ to $T+108 \mathrm{~h}$. Solid and dashed black lines denote subjectively identified $250-\mathrm{hPa}$ ridges and troughs, respectively.

trough extends from central Canada through the Intermountain West, whereas a downstream ridge extends from the Tennessee Valley to the Gulf of Mexico. At $T+$ 108 and $T+144 \mathrm{~h}$ (Figs. 3f,g), the meridional wind anomalies over North America exhibit a positive tilt, indicative of anticyclonic wave breaking and equatorward Rossby wave dispersion. 


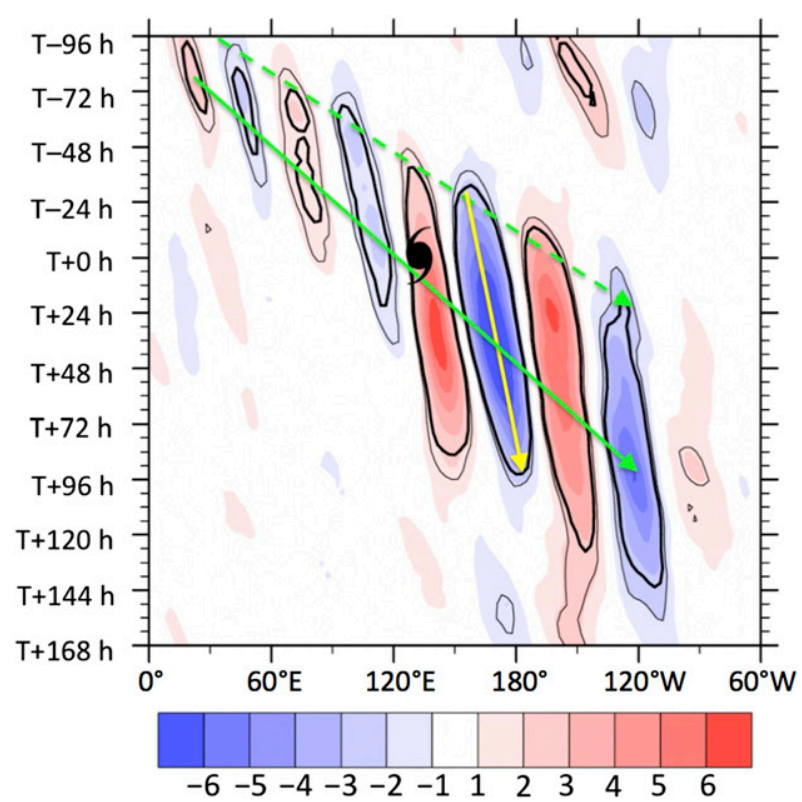

FIG. 4. Recurvature-relative composite Hovmöller diagram $\left(0^{\circ}-60^{\circ} \mathrm{W}\right)$ of the $35^{\circ}-60^{\circ} \mathrm{N}$ averaged $250-\mathrm{hPa}$ meridional wind anomaly (shaded, $\left.\mathrm{m} \mathrm{s}^{-1}\right)$ for all recurving WNP TCs $(N=292)$. Thin (thick) black contours denote statistical significance at the 95\% (99\%) confidence level. The dashed and solid green arrows indicate estimated zonal group speeds based on the leading edge $\left[c_{g}=42^{\circ}\right.$ day $\left.^{-1}\left(36.5 \mathrm{~m} \mathrm{~s}^{-1}\right)\right]$ and peak amplitude $\left[c_{g}=37^{\circ}\right.$ day $^{-1}$ $\left.\left(32.1 \mathrm{~m} \mathrm{~s}^{-1}\right)\right]$ of the RWT, respectively, whereas the yellow arrow indicates the estimated Rossby wave zonal phase speed $\left[c_{p}=\right.$ $6^{\circ}$ day $\left.^{-1}\left(5.2 \mathrm{~m} \mathrm{~s}^{-1}\right)\right]$. A reference latitude of $47.5^{\circ} \mathrm{N}$ is used to convert group and phase speeds from degree longitude per day to meters per second. The TC symbol denotes the longitude of the composite $\mathrm{TC}$ at recurvature.

To summarize the characteristics of the RWT, a Hovmöller diagram of $35^{\circ}-60^{\circ} \mathrm{N}$ latitudinally averaged $250-\mathrm{hPa}$ meridional wind anomalies is constructed (Fig. 4). Consistent with Fig. 3, Rossby wave dispersion from the longitudes of Europe and Asia to the longitudes of the North Pacific and North America is evident between $T-96$ and $T+96 \mathrm{~h}$. Also consistent with Fig. 3 , Rossby wave amplification is occurring at the time of TC recurvature. The RWT exhibits an estimated zonal group speed $\left(c_{g}\right)$ of $37^{\circ} \mathrm{day}^{-1}\left(32.1 \mathrm{~m} \mathrm{~s}^{-1}\right)$ based on the peak amplitude of the RWT, and $42^{\circ}$ day $^{-1}\left(36.5 \mathrm{~m} \mathrm{~s}^{-1}\right)$ based on the leading edge of the RWT. These speeds are comparable to those of RWTs associated with individual recurving WNP TCs [e.g., $c_{g}=40^{\circ}-50^{\circ}$ day $^{-1}$ for the RWT associated with TC Malakas (2010); Archambault (2011, p. 158)] and wintertime extratropical cyclones [e.g., $c_{g}=30^{\circ}$ day $^{-1}$; Szunyogh et al. (2002)]. The Rossby wave zonal phase speed is $6^{\circ} \mathrm{day}^{-1}\left(5.2 \mathrm{~m} \mathrm{~s}^{-1}\right)$. According to Fig. 4, recurving WNP TCs tend to be associated with a statistically significant RWT that affects approximately $240^{\circ}$ of longitude and persists for approximately 10 days, indicating a potentially important contribution by recurving TCs to Northern Hemispheric intraseasonal climate variability.

Based on the composite analysis of 1979-2009 recurving WNP TCs, the tendency for the North Pacific upper-level flow pattern to become significantly amplified following WNP TC recurvature, documented previously by Archambault et al. (2013), can be attributed to an RWT arriving from Asia that amplifies in concert with TC recurvature and disperses downstream across the North Pacific. Whether TC recurvature and RWT amplification are dynamically linked or merely coincident is addressed next in a comparison of the extratropical flow response to strong and weak TC-extratropical flow interactions.

\section{b. Extratropical flow response to strong versus weak interactions}

The extratropical flow response to strong TCextratropical flow interactions (i.e., recurving TCs associated with strong negative PV advection by the irrotational wind) is assessed by constructing interaction-relative composite analyses of strong interactions at 36 -h intervals for $T-72$ to $T+144 \mathrm{~h}$ relative to the time of maximum interaction (Fig. 5). For strong interactions, the average time of maximum interaction is $31 \mathrm{~h}$ after TC recurvature (Archambault et al. 2013, section 4e).

At $T-72 \mathrm{~h}$ (Fig. 5a), two preexisting RWTs are present over North and South Asia, similar to the composite of all recurving WNP TCs $72 \mathrm{~h}$ prior to recurvature (Fig. 3a). By $T-36 \mathrm{~h}$, the two RWTs merge into one RWT (Fig. 5b). This RWT then amplifies over the WNP between $T-36$ and $T+0 \mathrm{~h}$ as the divergent outflow of the recurving TC impinges upon the eastern flank of an upstream positively tilted trough over eastern China and the western flank of the adjacent downstream ridge embedded in the PV waveguide (Figs. 5b,c). The upstream trough and downstream ridge are nearly stationary between $T-36$ and $T+36 \mathrm{~h}$ (Figs. 5b-d), suggesting that the divergent outflow associated with the TC is acting to impede Rossby wave propagation.

Between $T+0$ and $T+72 \mathrm{~h}$, the RWT disperses across the North Pacific to North America, resulting in the development of a high-latitude ridge over western North America (Figs. 5c-e). This ridge persists through $T+108$ and $T+144 \mathrm{~h}$ (Figs. 5f,g). Cyclonic wave breaking is evinced by the overturning PV contours over the high-latitude North Pacific and Alaska, upstream of the developing high-latitude ridge, at $T+36$ and $T+72 \mathrm{~h}$ (Figs. 5d,e).

The extratropical flow response to weak TC-extratropical flow interactions (i.e., recurving TCs associated with weak negative PV advection by the irrotational wind) is evaluated by constructing composite analyses of 

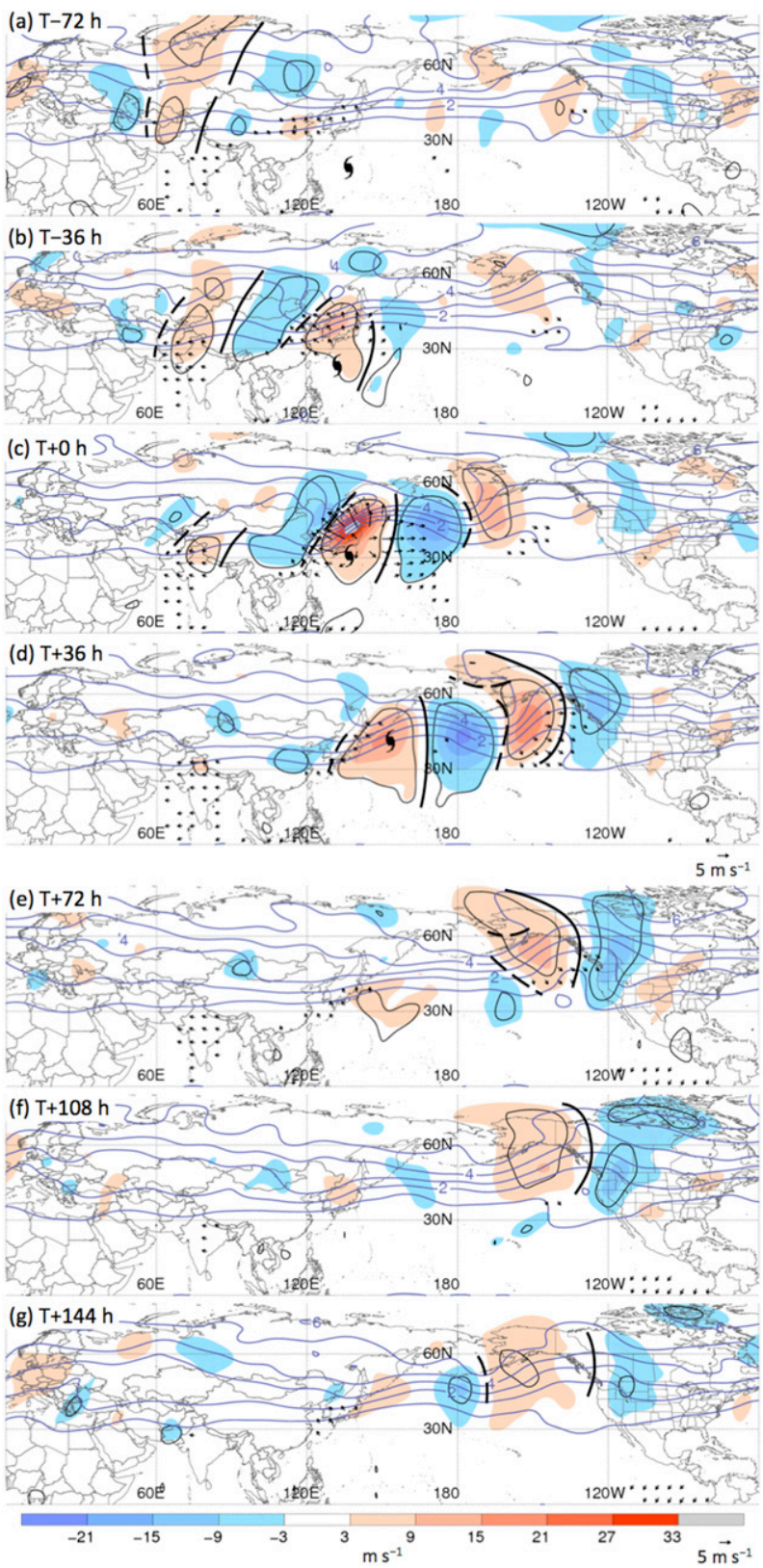

FIG. 5. Interaction-relative composite analyses of strong TCextratropical flow interactions $(N=54)$ at $36-\mathrm{h}$ intervals for $(\mathrm{a})-(\mathrm{g})$ $T-72$ to $T+144 \mathrm{~h}$. Analyses show $250-\mathrm{hPa}$ meridional wind anomalies (shaded according to the color bar, $\mathrm{m} \mathrm{s}^{-1}$; enclosed by black contours where significant at the $99 \%$ confidence level), PV (blue, every 1 PVU), and irrotational wind (vectors, $>2 \mathrm{~m} \mathrm{~s}^{-1}$ ). The TC symbol denotes the composite TC position, which is plotted for (a)-(d) $T-72$ to $T+36 \mathrm{~h}$. Solid and dashed black lines denote subjectively identified 250 -hPa ridges and troughs, respectively.

weak interactions at 36-h intervals for $T-72$ to $T+$ $36 \mathrm{~h}$ relative to the time of maximum interaction (Fig. 6). The average time of maximum interaction during weak interactions is $56 \mathrm{~h}$ after recurvature (Archambault et al. 2013, their section 4e).
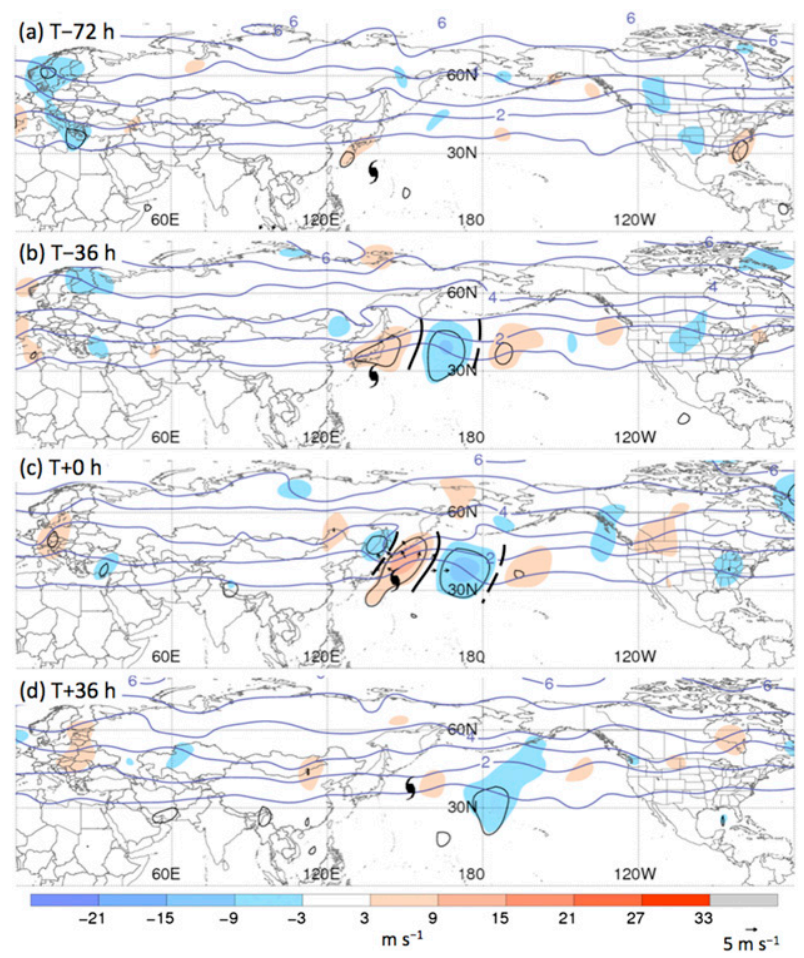

FIG. 6. As in Fig. 5, but for weak TC-extratropical flow interactions $(N=54)$ for (a)-(d) $T-72$ to $T+36 \mathrm{~h}$. The TC symbol denotes the composite TC position.

For weak interactions, at $T-72 \mathrm{~h}$ (Fig. 6a), no signature of amplified flow is apparent over Asia or the North Pacific, but by $T-36 \mathrm{~h}$ (Fig. 6b), a ridge-trough couplet in the waveguide has formed downstream of the recurving TC over the western and central North Pacific. Divergent outflow from the TC does not appear to be influencing the waveguide at either $T-72$ or $T-36 \mathrm{~h}$. By $T+0$ h (Fig. 6c), however, weak divergent outflow from the recurving TC impinges upon the eastern flank of an upstream trough and western flank of the aforementioned ridge (Fig. 6c). Note that the upstream trough and downstream ridge-trough couplet together constitute a weak RWT. By $T+36$ h (Fig. 6d), the RWT has weakened, with significant meridional wind anomalies only associated with the downstream ridge over the central North Pacific. By $T+72 \mathrm{~h}$, these meridional wind anomalies have disappeared (not shown). In summary, during weak interactions, a RWT briefly amplifies in situ but soon dissipates over the westerncentral North Pacific.

The formation of baroclinic surface cyclones is an important aspect of Rossby wave dispersion (e.g., Simmons and Hoskins 1979; Hakim 2005) that has been speculated to influence the strength of the downstream midlatitude impact of TC recurvature (e.g., Riemer and Jones 2010). To examine surface cyclone development downstream of 


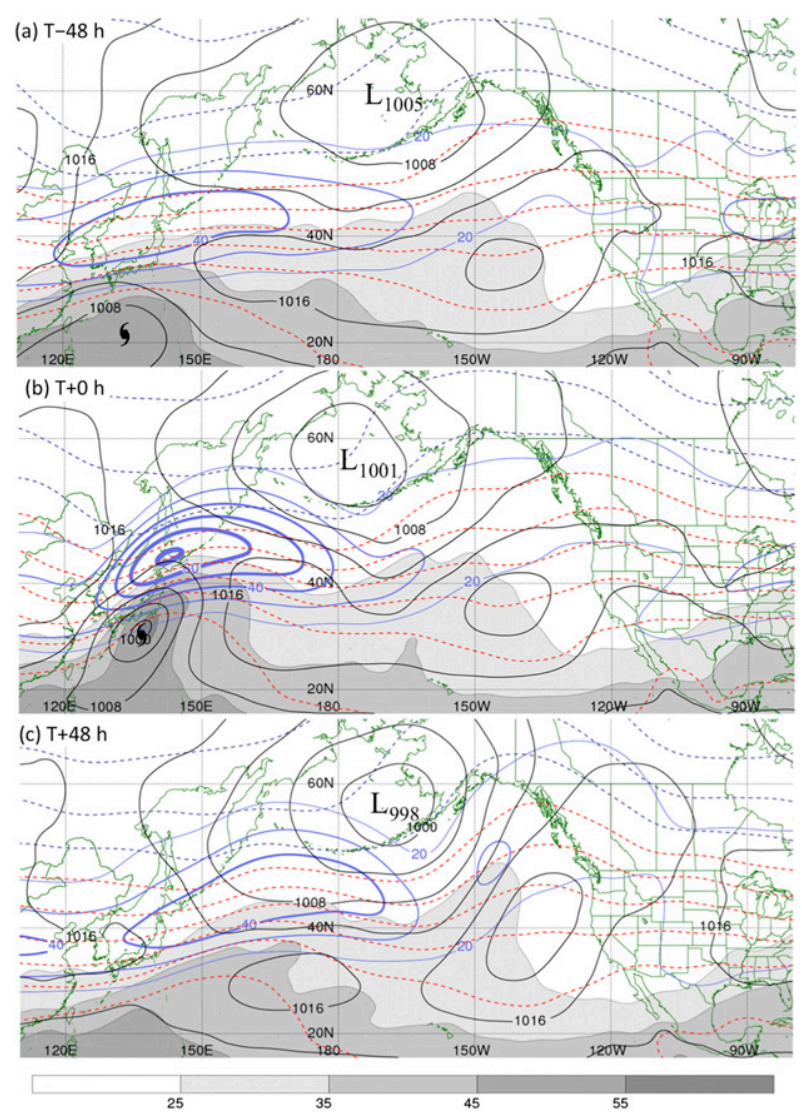

FIG. 7. Interaction-relative composite analyses of strong TCextratropical flow interactions $(N=54)$ for (a) $T-48$, (b) $T+0$, and (c) $T+48 \mathrm{~h}$. Analyses show total-column precipitable water (shaded according to grayscale, $\mathrm{mm}$ ), sea level pressure (black, every $4 \mathrm{hPa}$ ), 1000-500-hPa thickness (dashed red, except dashed blue for values $<540$ dam; every 6 dam), and 250 -hPa wind speed (solid blue, every $10 \mathrm{~m} \mathrm{~s}^{-1}$ starting at $20 \mathrm{~m} \mathrm{~s}^{-1}$ ). The TC symbol denotes the composite TC position, which is plotted for (a) $T-48$ and (b) $T+$ $0 \mathrm{~h}$. The "L" symbol denotes the location and minimum sea level pressure $(\mathrm{hPa})$ of a downstream surface cyclone.

recurving TCs during strong interaction cases, composite analyses of precipitable water, sea level pressure, 1000500-hPa thickness, and $200-\mathrm{hPa}$ wind speed are constructed at 48 -h intervals surrounding the time of maximum interaction (Fig. 7).

Between $T-48$ and $T+0 \mathrm{~h}$ (Figs. 7a,b), a jet streak intensifies poleward of the recurving TC as indicated by the dramatic increase in the $200-\mathrm{hPa}$ wind speed maximum from 40 to $70 \mathrm{~m} \mathrm{~s}^{-1}$. A downstream surface cyclone forms in association with the jet intensification: a broad, weak surface low over the Bering Sea at $T-48 \mathrm{~h}$ (Fig. 7a) shifts westward while deepening from 1005 to $1001 \mathrm{hPa}$ by $T+0 \mathrm{~h}$ (Fig. 7b) such that the cyclone is collocated with the poleward exit region of the jet. By $T+48 \mathrm{~h}$ (Fig. 7c), the surface low deepens further to $998 \mathrm{hPa}$. The development of the surface cyclone is consistent with ongoing cyclonic wave breaking in the same region (e.g., Fig. 5d).

Between $T+0$ and $T+48 \mathrm{~h}$ (Figs. 7b,c), warm air advection over the Gulf of Alaska and northwestern North America, inferred by the surface geostrophic wind directed across the 1000-500-hPa thickness gradient toward lower thicknesses, increases as the surface cyclone deepens. The warm air advection is consistent with ridge amplification over western North America evident in the strong interaction composite (Fig. 5). In addition, the slight poleward surge of moisture over the eastern Pacific at $T+48 \mathrm{~h}$ (Fig. 7c) suggests that diabatic heating associated with clouds and precipitation may enhance ridge amplification.

For comparison with strong interactions, the same analyses in Fig. 7 are constructed for the period surrounding weak interactions (not shown). In contrast to strong interactions, downstream surface cyclone development is not evident during weak interactions. The lack of a downstream cyclone development may partially explain why the downstream impact of weak interactions is less than of strong interactions.

\section{c. Synoptic signatures of strong versus weak interactions}

The key synoptic signatures of strong and weak TCextratropical flow interactions at the time of maximum interaction are illustrated in Figs. 8a and 8b, respectively. The upper-level features are displayed at $200 \mathrm{hPa}$ because the TC-extratropical flow interaction is best defined at this level. For both types of interactions, $500-\mathrm{hPa}$ ascent is located over and northeast of the recurving TC on the leading edge of a poleward-directed moisture plume that features precipitable water values of at least $45 \mathrm{~mm}$. The northeastward displacement of ascent relative to the center of the TC is characteristic of a TC undergoing ET and likely reflects the slantwise ascent of air parcels within a nascent warm conveyor belt (e.g., Klein et al. 2000; Grams et al. 2013a). The ascent is collocated with the equatorward entrance region of an anticyclonically curved jet streak indicated by a $200-\mathrm{hPa}$ wind speed maximum. Divergent outflow associated with the TC impinges upon the eastern flank of an upstream, positively tilted trough and the western flank of a downstream ridge embedded in the PV waveguide. The ascent and divergent outflow associated with the TC act to reinforce the ascent and cross-PV contour flow that are typical of a jet entrance region.

Subtle differences exist in the configurations of the extratropical flow pattern relative to the recurving TC for strong and weak TC-extratropical flow interactions at the time of maximum interaction. During strong interactions, the recurving TC is situated downstream of 


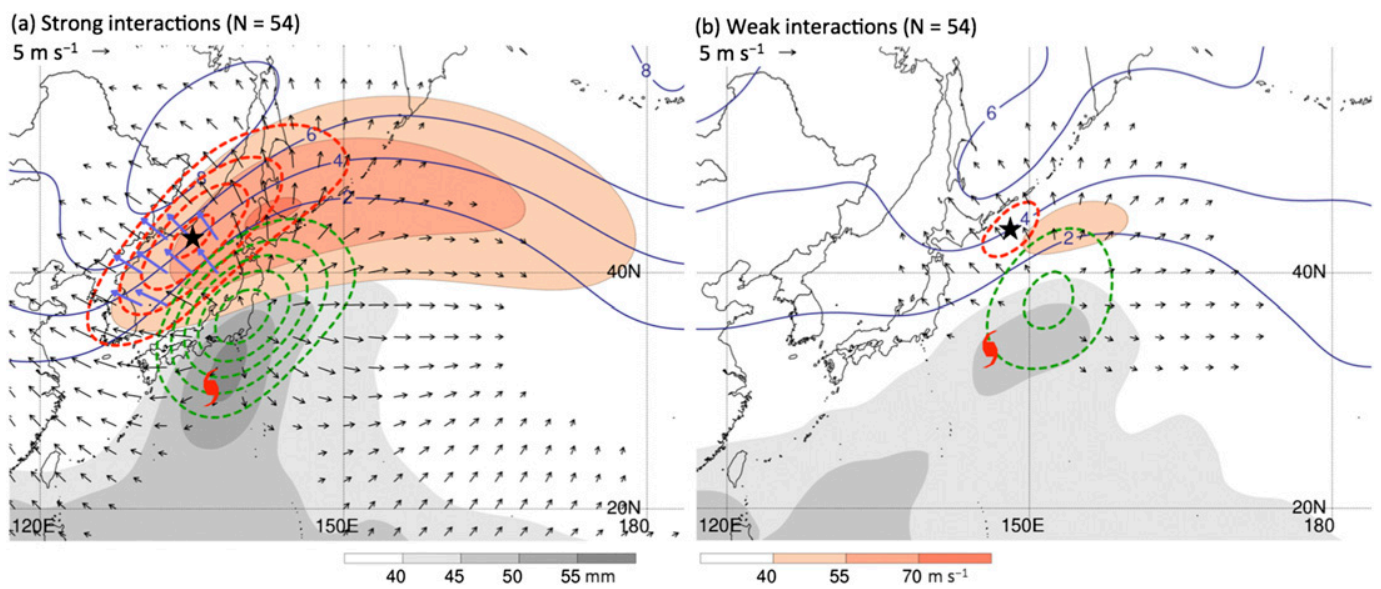

FIG. 8. Interaction-relative composite analyses showing (a) strong $(N=54)$ and (b) weak $(N=54)$ TCextratropical flow interactions at the time of maximum interaction. Analyses show 500-hPa ascent (dashed green, every $2 \times 10^{-3} \mathrm{hPa} \mathrm{s}^{-1}$, negative values only), total-column precipitable water (shaded according to grayscale, mm), 200-hPa PV (blue, every 1 PVU), irrotational wind (vectors, $>2 \mathrm{~m} \mathrm{~s}^{-1}$; purple vectors, $>8 \mathrm{~m} \mathrm{~s}^{-1}$ ), negative PV advection by the irrotational wind (dashed red, every 2 PVU day ${ }^{-1}$ starting at $-2 \mathrm{PVU} \mathrm{day}^{-1}$ ), and total wind speed (shaded according to color bar, $\mathrm{m} \mathrm{s}^{-1}$ ). The star denotes the point of maximum interaction. The TC symbol denotes the composite TC position.

a relatively strong and broad PV trough (Fig. 8a), whereas during weak interactions the recurving $\mathrm{TC}$ is closer to the base of a relatively weak and narrow PV trough (Fig. 8b). As shown previously in Fig. 2, for strong interactions, the point where the divergent outflow impinges most strongly on the PV gradient (i.e., the point of maximum interaction) is north and slightly west of the TC center (Fig. 8a), whereas during weak interactions, this point is less far north and is slightly east of the TC (Fig. 8b). Of interest is that strong interactions may be analogous to the extratropical reintensification scenario associated with recurving TCs encountering a "northwest" midlatitude circulation pattern documented by Harr et al. (2000): in their compositing study, Harr et al. (2000) find that TCs recurving ahead of an upstream midlatitude trough (a northwest pattern) are favored to reintensify as extratropical cyclones. In contrast, the position of the TC center near the base of a trough during weak interactions is reminiscent of scenarios in which a recurving TC dissipates before completing ET [e.g., the case of TC Jangmi (2008) described in Grams et al. (2013b) and the idealized scenarios of Ritchie and Elsberry (2007)].

From a composite analysis perspective, the ascent, moisture plume, divergent outflow, and jet streak associated with the recurving TC are all greatly enhanced for strong interactions relative to weak interactions (Figs. 8a,b). These apparent differences are corroborated by an analysis of the maximum magnitudes of various quantities for the individual cases in each composite (Table 2). Relative to weak interactions, strong interactions feature significantly larger negative PV advection by the irrotational wind (by definition), stronger ascent coinciding with higher precipitable water values, and stronger irrotational and total wind speeds.

\section{d. Dynamics of strong versus weak interactions}

To assess midlevel frontogenesis and forcing for ascent, 700-hPa $\mathbf{Q}$ vectors and $\mathbf{Q}$-vector divergence are evaluated using natural-coordinate partitioning at the time of maximum interaction for strong (Figs. 9a,c,e) and weak (Figs. 9b,d,f) interactions. The $\mathbf{Q}$-vector patterns are generally similar for both types of interactions. In both the strong and weak interaction composites (Figs. 9a,b), Q vectors exhibit an eastward-directed component across a trough and a westward-directed component across a downstream ridge. This $\mathbf{Q}$-vector pattern corresponds to $\mathbf{Q}$-vector convergence (i.e., forcing for ascent) on the eastern flank of the trough and western flank of the ridge. The region of forcing for ascent closely aligns with midlevel ascent for both strong interactions (cf. Fig. 9a and Fig. 8a) and weak interactions (cf. Fig. 9b and Fig. 8b).

Some crucial differences in the $\mathbf{Q}$ vector and $\mathbf{Q}$-vector divergence patterns between strong and weak interactions are apparent. During strong interactions, $\mathbf{Q}$ vectors are substantially larger than during weak interactions (cf. Figs. 9a,b). In addition, Q-vector convergence northeast of the TC and just ahead of a 700-hPa trough is more expansive and stronger for strong interactions than for weak interactions, which is consistent with the stronger midlevel ascent and corresponding stronger 


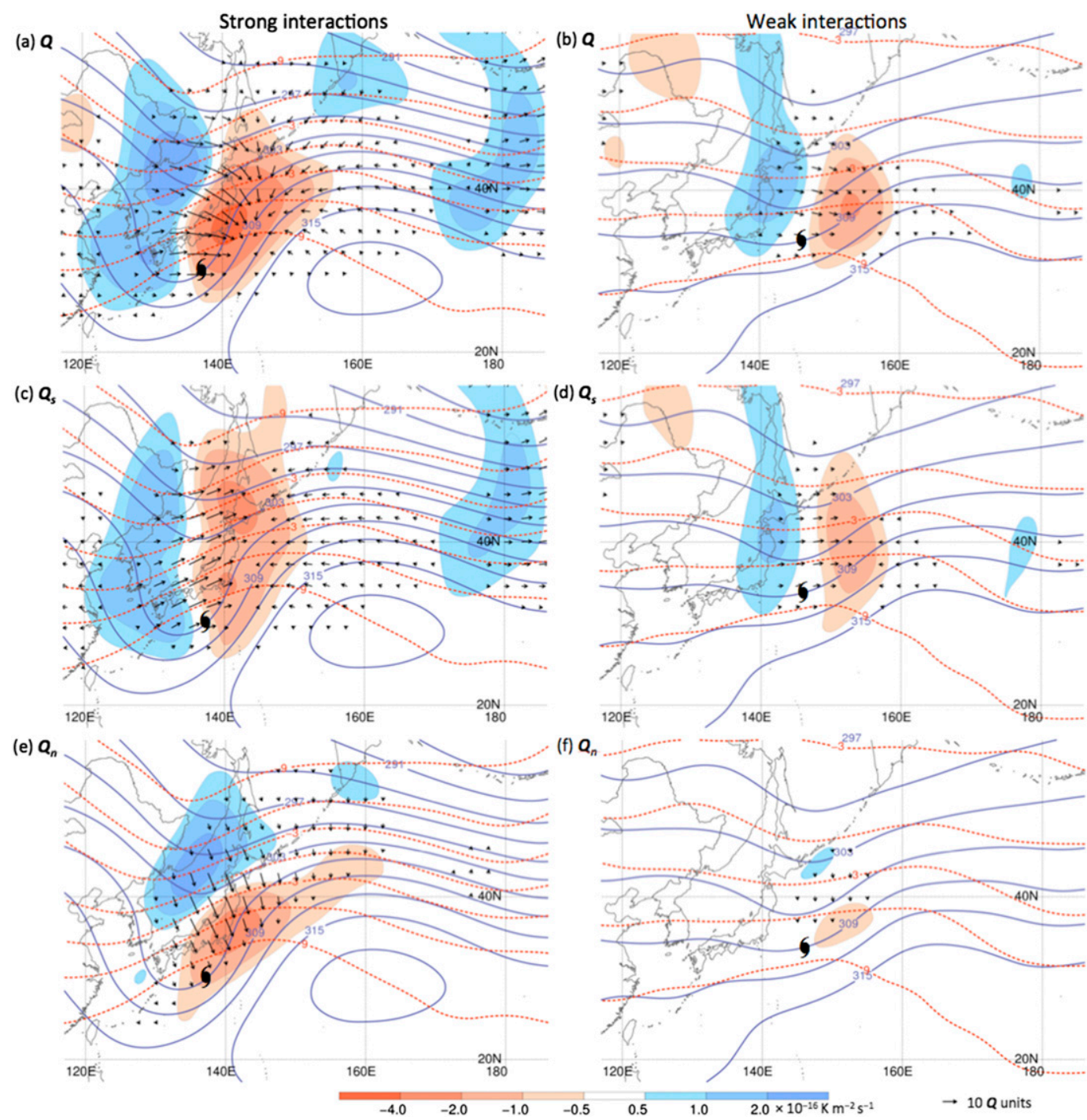

FIG. 9. Interaction-relative composite analyses for (a),(c),(e) strong $(N=54)$ and (b),(d),(f) weak $(N=54)$ TC-extratropical flow interactions at the time of maximum interaction. Analyses show $700-\mathrm{hPa} \mathbf{Q}$ (vectors, $>2 \times 10^{-11} \mathrm{~K} \mathrm{~m}^{-1} \mathrm{~s}^{-1}$ ), divergence of $\mathbf{Q}$ (shaded according to color bar, $10^{-16} \mathrm{~K} \mathrm{~m}^{-2} \mathrm{~s}^{-1}$ ), geopotential height (solid blue, every $3 \mathrm{dam}$ ), and temperature (dashed red, every $3^{\circ} \mathrm{C}$ ). The TC symbol denotes the composite TC position. In (c),(d) $\mathbf{Q}_{s}$ and (e),(f) $\mathbf{Q}_{n}$ instead of $\mathbf{Q}$ are displayed and used to compute the divergence of $\mathbf{Q}$.

divergent outflow associated with strong interactions than with weak interactions (Fig. 8 and Table 2). The maximum magnitudes of $\mathbf{Q}$ vectors and the maximum values of $\mathbf{Q}$-vector convergence tend to be larger for strong interactions than for weak interactions (Figs. 10a,b, respectively).

The $\mathbf{Q}$-vector signatures are investigated in more detail in composite analyses of $\mathbf{Q}_{s}$ vectors and $\mathbf{Q}_{s}$-vector divergence (Figs. 9c,d), and $\mathbf{Q}_{n}$ vectors and $\mathbf{Q}_{n}$-vector divergence (Fig. 9e,f). During strong interactions (Fig. 9c), the $\mathbf{Q}_{s}$-vector pattern favors counterclockwise rotation of isotherms over and poleward of the TC, where $Q_{s}>0$, and favors clockwise rotation farther downstream, where
$Q_{s}<0$. Such a $\mathbf{Q}_{s}$-vector pattern indicates amplification of a thermal ridge (e.g., Martin 1999, 2006). A meridionally elongated region of $\mathbf{Q}_{s}$-vector convergence associated with forcing for ascent is evident just downstream of the trough axis in the geopotential height field.

During weak interactions (Fig. 9d), the patterns of $\mathbf{Q}_{s}$ vectors and $\mathbf{Q}_{s}$-vector divergence are similar to the strong interaction composite (Fig. 9c), but less pronounced. The $\mathbf{Q}_{s}$-vector pattern indicates weak thermal ridge amplification and is associated with a smaller region of $\mathbf{Q}_{s}$-vector convergences, indicating less $\mathbf{Q}_{s}$-vector forcing for ascent and associated divergent outflow during weak interactions than strong interactions. Consistent 
TABLE 2. The means and standard deviations of the maximum values of various quantities for strong $(N=54)$ and weak $(N=54)$ TCextratropical flow interactions at the time of maximum interaction. The differences between strong and weak interactions for each quantity are significant at the $99.9 \%$ confidence level based on a two-sided Wilcoxon-Mann-Whitney rank-sum test.

\begin{tabular}{|c|c|c|}
\hline & Strong & Weak \\
\hline $\begin{array}{l}\text { 250-150-hPa layer-averaged negative PV advection by } \\
\text { irrotational wind (PVU day }{ }^{-1} \text { ) }\end{array}$ & $-9.5 \pm 2.1$ & $-3.4 \pm 1.5$ \\
\hline 500-hPa ascent $\left(\mathrm{hPa} \mathrm{s}^{-1}\right)$ & $-7.7 \pm 2.9 \times 10^{-3}$ & $-4.6 \pm 1.9 \times 10^{-3}$ \\
\hline Total-column precipitable water (mm) & $66.4 \pm 8.1$ & $60.0 \pm 8.4$ \\
\hline $250-150-\mathrm{hPa}$ layer-averaged irrotational wind speed $\left(\mathrm{m} \mathrm{s}^{-1}\right)$ & $10.6 \pm 2.3$ & $6.1 \pm 1.8$ \\
\hline 200-hPa total wind speed $\left(\mathrm{m} \mathrm{s}^{-1}\right)$ & $80.4 \pm 11.7$ & $58.8 \pm 13.1$ \\
\hline
\end{tabular}

with the signatures in Figs. 8c,d, the maximum magnitudes of $\mathbf{Q}_{s}$ vectors and the maximum values of $\mathbf{Q}_{s}$-vector convergence are smaller than for strong interactions (Figs. 10a,b, respectively).

During strong interactions (Fig. 9e), frontogenesis is indicated by large $\mathbf{Q}_{n}$ vectors pointing toward warm air in a broad region extending eastward from the trough axis to the crest of the downstream ridge in the geopotential height field. The region of $\mathbf{Q}_{n}$-vector convergence over and northeast of the TC along the eastern flank of the trough indicates frontogenetical forcing for ascent, which is consistent with the formation of a warm front and warm conveyor belt in the northeast quadrant of a TC as it undergoes the transformation stage of ET (e.g., Klein et al. 2000; Harr and Elsberry 2000). During weak interactions (Fig. 9f), weak frontogenesis is indicated by small $\mathbf{Q}_{n}$ vectors pointing toward warm air along the eastern flank of the trough. The region of
$\mathbf{Q}_{n}$-vector convergence is small, indicating little frontogenetical forcing for ascent. As indicated by Figs. 9e,f, the maximum magnitudes of $\mathbf{Q}_{n}$ vectors and the maximum values of $\mathbf{Q}_{n}$-vector convergence both tend to be smaller than those for strong interactions (Figs. 10a and $10 \mathrm{~b}$, respectively).

For both strong and weak interactions, the maximum value of $\mathbf{Q}_{n}$-vector convergence tends to be larger than that of $\mathbf{Q}_{s}$-vector convergence (Fig. 10b). These differences are statistically significant at the $99 \%$ confidence level (not shown). The composite analysis of strong interactions fits with these findings (cf. Figs. 9c and 9e), but the composite analysis of weak interactions would suggest that the composite maximum value of $\mathbf{Q}_{n}$-vector convergence is smaller than the composite maximum value of $\mathbf{Q}_{s}$-vector convergence (cf. Figs. 9d and 9f). This incongruity illustrates the risk of inferring the maximum magnitude of a quantity based on a composite mean (a)

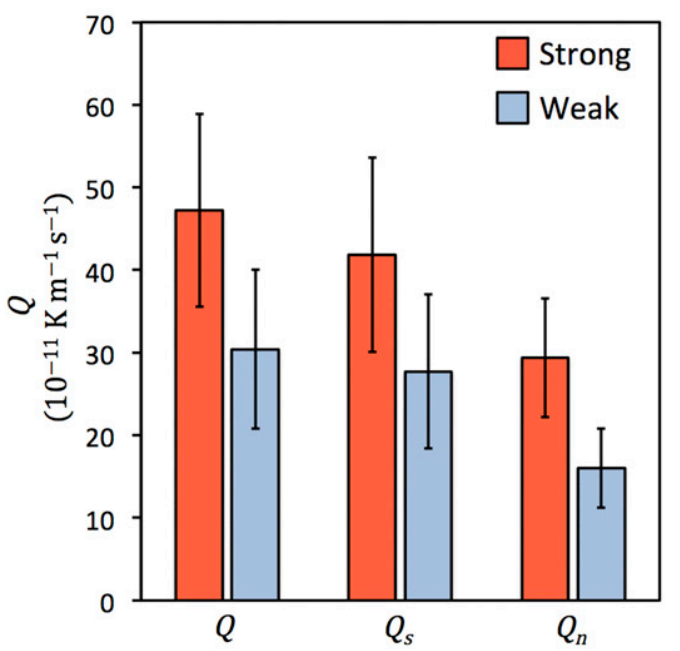

(b)

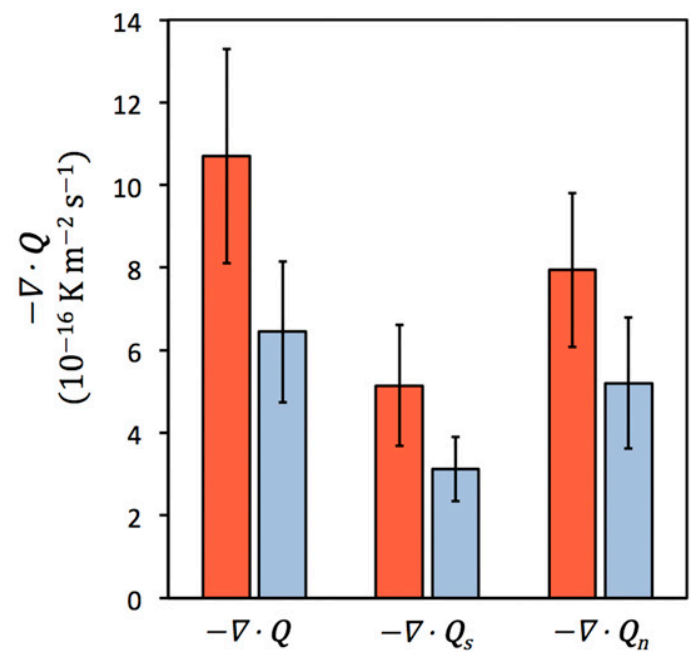

FIG. 10. The means (bars) and standard deviations (whiskers) of (a) the maximum magnitudes of $\mathbf{Q}, \mathbf{Q}_{s}$, and $\mathbf{Q}_{n}$ $\left(10^{-11} \mathrm{~K} \mathrm{~m}^{-1} \mathrm{~s}^{-1}\right)$ and (b) the maximum values of the convergence of $\mathbf{Q}, \mathbf{Q}_{s}$, and $\mathbf{Q}_{n}\left(10^{-16} \mathrm{~K} \mathrm{~m}^{-2} \mathrm{~s}^{-1}\right)$ at $700 \mathrm{hPa}$ for strong $(N=54)$ and weak $(N=54)$ TC-extratropical flow interactions at the time of maximum interaction. The differences between strong and weak interactions for each quantity are significant at the $99.9 \%$ confidence level based on a two-sided Wilcoxon-Mann-Whitney rank-sum test. 
rather than on the mean of the maximum magnitudes for the cases constituting the composite.

The $\mathbf{Q}$-vector analysis described above can be compared with that of Harr and Elsberry (2000), who employed natural-coordinate $\mathbf{Q}$-vector partitioning to examine two kinds of WNP ET cases: one where an ex-TC [David (1997)] undergoes extratropical reintensification, and the other where an ex-TC [Opal (1997)] decays. While the $\mathbf{Q}_{n}$-vector patterns for the two ex-TCs are similar, the $\mathbf{Q}_{s}$-vector pattern favors thermal wave amplification in advance of David, but does not favor thermal wave amplification in advance of Opal. Harr and Elsberry (2000) interpret the $\mathbf{Q}_{s}$-vector patterns as indicative of favorable and unfavorable phasing, respectively, between the TC and the extratropical flow that contributes to the extratropical reintensification of David and to the decay of Opal. The differences between $\mathbf{Q}_{s}$-vector patterns for strong and weak TC-extratropical flow interactions shown here thus resemble the differences between $\mathbf{Q}_{s}$-vector patterns for extratropical reintensification and decay scenarios of ET described by Harr and Elsberry (2000).

The propagation of the upstream trough and amplification of the downstream ridge in the vicinity of the recurving TC are explored for strong and weak TCextratropical flow interactions in the context of PV advection (Fig. 11). In the strong interaction case, negative PV advection upstream of the trough axis and positive PV advection downstream of the trough axis serve to propagate the trough eastward (Fig. 11a). However, the magnitude of the positive PV advection is reduced compared with that of negative PV advection, suggesting that the propagation of the trough is being impeded along its eastern flank. In addition, the presence of a small region of negative PV advection within the downstream ridge indicates amplification of the ridge.

To examine the roles of the nondivergent and irrotational wind in trough propagation and ridge amplification, analyses are produced of the negative PV advection by the nondivergent wind and irrotational wind (Figs. 11c and 11e, respectively). It is found that negative $\mathrm{PV}$ advection by the irrotational wind along the eastern flank of the trough and western flank of the ridge (Fig. 11e) strongly opposes positive PV advection by the nondivergent wind (Fig. 11c), resulting in a maximum value of positive $\mathrm{PV}$ advection by the total wind that is only $55 \%$ of the maximum value of positive PV advection by the nondivergent wind (Table 3 ). Thus, the divergent outflow impedes the forward progression of the trough, allowing the downstream ridge to remain in place (i.e., become anchored). In addition, the negative PV advection by the irrotational wind within the ridge on its western side promotes an amplification of the ridge. Therefore, the divergent outflow is critical to countering propagation by the nondivergent wind and serves to anchor and amplify the ridge during strong interactions.

During weak interactions, the magnitudes of the negative and positive PV advection by the full wind about the trough axis are comparable (Fig. 11b), indicating that the eastward propagation of the trough is not being severely impeded. Indeed, the PV advection by the irrotational wind (Fig. 11f) on the eastern flank of the trough and western flank of the ridge only weakly opposes the positive PV advection by the nondivergent wind (Fig. 11d), resulting in a maximum value of positive $\mathrm{PV}$ advection by the total wind that is $79 \%$ of the maximum value of positive PV advection by the nondivergent wind (Table 3 ). In addition, negative PV advection by the irrotational wind does not appear to contribute to ridge amplification. Based on these PV advection analyses, it is therefore inferred that the divergent outflow associated with the TC is substantially more important in hindering trough propagation and contributing to ridge anchoring and amplification during strong interactions than during weak interactions.

Potential vorticity frontogenesis by the total, nondivergent, and irrotational wind is examined for strong and weak TC-extratropical flow interactions (Fig. 12) to diagnose jet streak intensification. Because PV frontogenesis is computed over an isobaric layer from the horizontal wind only, neither vertical motion nor nonconservative effects are considered in the calculation. The composite analysis indicates that for both strong interactions (Fig. 12a) and weak interactions (Fig. 12b), the overlap of PV frontogenesis with the strongest PV gradient [i.e., $>1$ PVU $(100 \mathrm{~km})^{-1}$ ] and the entrance region of the jet streak (Figs. 8a,b) supports jet streak intensification. However, PV frontogenesis in the strong interaction composite analysis (Fig. 12a) is more pronounced than in the weak interaction composite analysis (Fig. 12b), and the maximum magnitudes of PV frontogenesis by the total, nondivergent, and irrotational wind are all larger during strong interactions than during weak interactions (Fig. 13).

During strong interactions, based on the overlap of PV frontogenesis with the strongest PV gradient, the irrotational wind is at least as important as the nondivergent wind in intensifying the jet streak (cf. Figs. 12e and 12c). This finding is consistent with the finding by Cordeira (2011, p. 108) that during the recurvature of WNP TC Dale (1996), a strong interaction case (Archambault et al. 2013, their Table 2), the irrotational wind is critical to PV frontogenesis associated with the intensification of a $110 \mathrm{~m} \mathrm{~s}^{-1}$ jet streak. In contrast, for weak interactions, the nondivergent wind is more important than the 


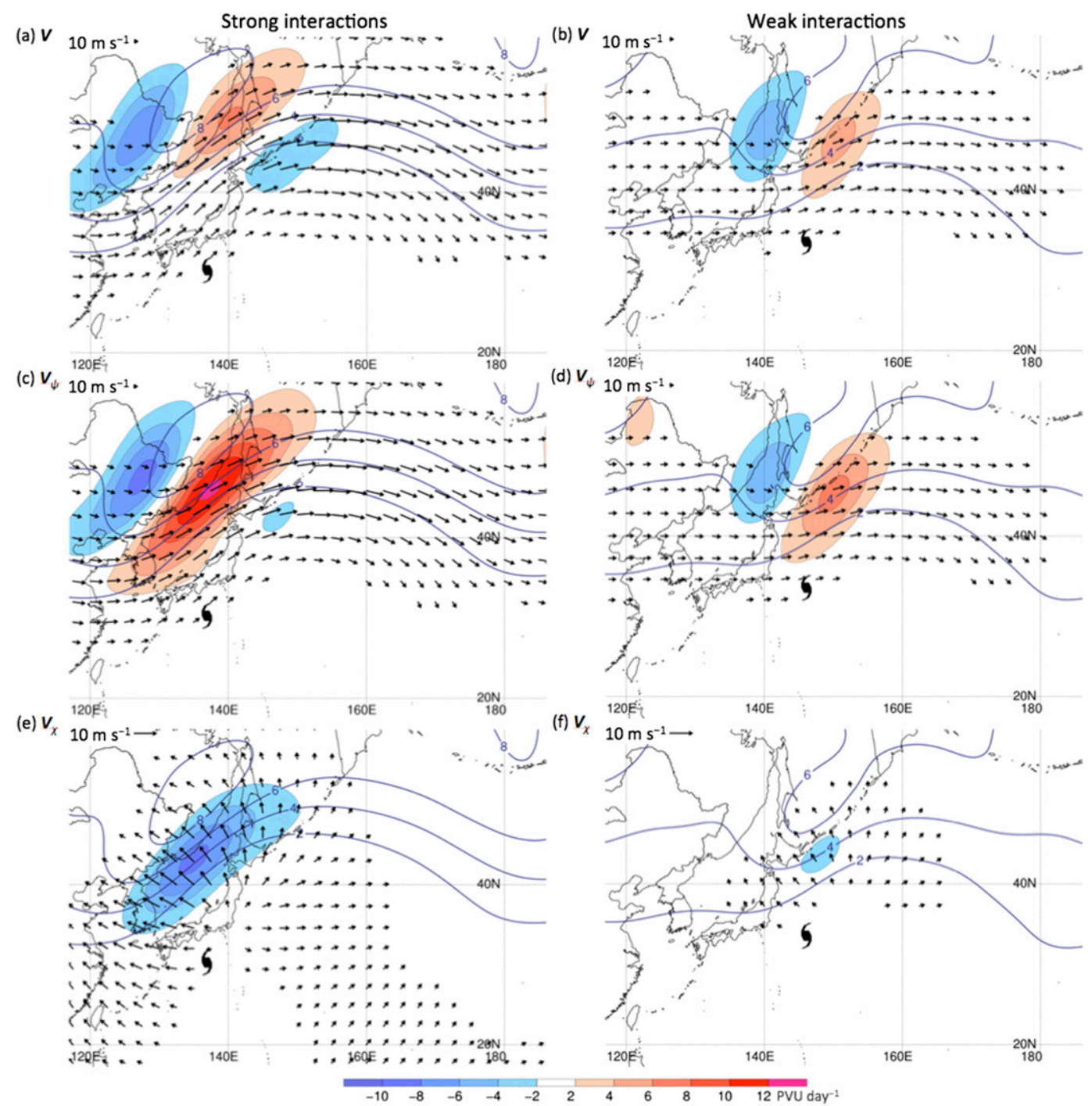

FIG. 11. Interaction-relative composite analyses for (a),(c),(e) strong $(N=54)$ and (b),(d),(f) weak $(N=54)$ TCextratropical flow interactions at the time of maximum interaction. Analyses show 250-150-hPa layer-averaged PV advection (shaded according to color bar, $\mathrm{PVU} \mathrm{day}{ }^{-1}$ ), PV (contours, every $2 \mathrm{PVU}$ ), and wind (vectors, $\mathrm{m} \mathrm{s}^{-1}$ ). The TC symbol denotes the composite TC position. In (a),(b) the total and (c),(d) the nondivergent wind are used to compute PV advection and are plotted for values $>18 \mathrm{~m} \mathrm{~s}^{-1}$, whereas in (e),(f), the irrotational wind is used to compute PV advection and is plotted for values $>2 \mathrm{~m} \mathrm{~s}^{-1}$.

irrotational wind in jet streak intensification (cf. Figs. 12d and $12 \mathrm{~b}$ ), with the irrotational wind appearing to contribute to a slight weakening of the jet streak (Fig. 12f). Therefore, during strong interactions, divergent outflow plays a more prominent role in intensifying the jet streak than during weak interactions.

\section{Discussion}

The tendency for a preexisting RWT to amplify and migrate downstream in association with the recurvature of a WNP TC corroborates findings of a recent climatology (Archambault et al. 2013), case studies (e.g., Harr and Dea 2009; Reynolds et al. 2009; Anwender et al. 2010; Grams et al. 2013b), and idealized modeling studies (e.g., Riemer et al. 2008; Riemer and Jones 2010) that recurving WNP TCs are often associated with extratropical flow amplification. To the authors' knowledge, the present study is the first to demonstrate from a composite perspective that recurving WNP TCs are associated with the amplification of a preexisting RWT that disperses downstream and alters the large-scale flow pattern over North America.

The TC-extratropical flow interaction during TC recurvature can be characterized based on the negative 
TABLE 3. The means and standard deviations of the maximum values of the $250-150-\mathrm{hPa}$ layer-averaged positive PV advection by the total wind and by the nondivergent wind, respectively, and the ratios between the means, for strong $(N=54)$ and weak $(N=54)$ TC extratropical flow interactions at the time of maximum interaction. The differences between strong and weak interactions for each quantity are significant at the $99.9 \%$ confidence level based on a two-sided Wilcoxon-Mann-Whitney rank-sum test.

\begin{tabular}{lrr}
\hline \hline & Strong & Weak \\
\hline Positive PV advection by total wind (PVU day $\left.{ }^{-1}\right)$ & $8.4 \pm 3.6$ & $7.0 \pm 4.8$ \\
Positive PV advection by nondivergent wind $\left(\mathrm{PVU} \mathrm{day}^{-1}\right)$ & $15.4 \pm 4.1$ & $8.9 \pm 4.1$ \\
$\quad$ Positive PV advection by total wind & 0.55 & 0.79 \\
\hline Positive PV advection by nondivergent wind & & \\
\hline
\end{tabular}

PV advection by the irrotational wind associated with the TC (Archambault et al. 2013). In this framework, strong interactions are associated with a preexisting RWT that amplifies in conjunction with downstream baroclinic cyclogenesis and initiates large-scale flow anomalies downstream over North America. On the other hand, weak interactions are associated with a RWT that briefly amplifies in situ but dissipates prior to reaching North America. Therefore, consistent with Archambault et al. (2013), the downstream amplification of the extratropical flow pattern following TC recurvature is sensitive to the strength of the TC-extratropical flow interaction.

The dynamical connection between divergent outflow impinging upon the PV waveguide and Rossby wave amplification highlighted by this study is consistent with previous findings that the negative PV (or negative absolute vorticity) advection by the irrotational wind acts as a Rossby wave source (e.g., Sardeshmukh and Hoskins 1988; Riemer et al. 2008; Riemer and Jones 2010; Hodyss and Hendricks 2010). The PV framework used to diagnose Rossby wave amplification and dispersion in this study is complementary to the energetics framework used to diagnose downstream baroclinic development (Orlanski and Sheldon 1995) associated with Rossby wave dispersion following WNP extratropical cyclogenesis (e.g., Hakim 2003; Danielson et al. 2006) and TC recurvature (e.g., Harr and Dea 2009; Cordeira and Bosart 2010; Keller et al. 2014).

The finding that the downstream flow response to strong TC-extratropical flow interactions is stronger than for weak interactions is consistent with the tendency for strong interactions to be associated with stronger dynamics. Strong interactions are associated with a more distinct upstream trough associated with a preexisting RWT migrating from Asia, stronger midlevel forcing for ascent and frontogenesis, stronger upper-level PV frontogenesis and jet intensification, and more distinct downstream cyclone development. These findings are consistent with previous findings that compared with weak interactions, strong interactions tend to occur later in the primary recurving TC season (24 September vs 18 August; Archambault et al. 2013) when the WNP is characterized by enhanced baroclinicity and features stronger and more frequent midlatitude troughs.

The tendency for strong interactions to exhibit stronger ascent in conjunction with stronger and broader divergent outflow than weak interactions is consistent with the tendency for strong interactions to be associated with larger and more intense TCs at recurvature than weak interactions noted by Archambault et al. (2013, their section 4e). Compared with smaller and weaker TCs, larger and more intense TCs are more resilient to strong vertical wind shear as they recurve, and tend to generate larger total vertical mass flux in strong vertical wind shear in conjunction with heavier precipitation, stronger diabatic heating, and stronger upper-level divergence (Davis et al. 2008).

This study indicates that, in a composite sense, divergent outflow associated with the TC facilitates favorable phasing of the TC with the extratropical flow pattern by anchoring and amplifying a downstream ridge while hindering the eastward propagation of an upstream trough. This finding corroborates previous case studies (e.g., Grams et al. 2013a,b; Pantillon et al. 2014) indicating that the anchoring and amplification of a downstream ridge by the divergent outflow is intrinsic to ET. Based on the composite analysis of strong TC-extratropical flow interactions, the collocation of the ascent and outflow with the equatorward entrance region of the jet stream indicates that the divergent circulation acts to reinforce the ascent and cross-PV contour flow that characterize a jet entrance region. Strong interactions are hypothesized to represent a synergistic coupling between the recurving TC and the extratropical flow that in some instances helps maintain the divergent circulation of the TC, thus potentially mitigating the decay of the poleward-moving TC as it encounters lower sea surface temperatures and strong vertical wind shear. This synergistic coupling between the TC and extratropical flow is similar to that noted by Bosart and Lackmann (1995) for the case of Atlantic TC David (1979). In the case of David (1979), diabatic ridge amplification shortens the half wavelength between the upstream trough and downstream ridge, thereby enhancing differential cyclonic vorticity advection over the 


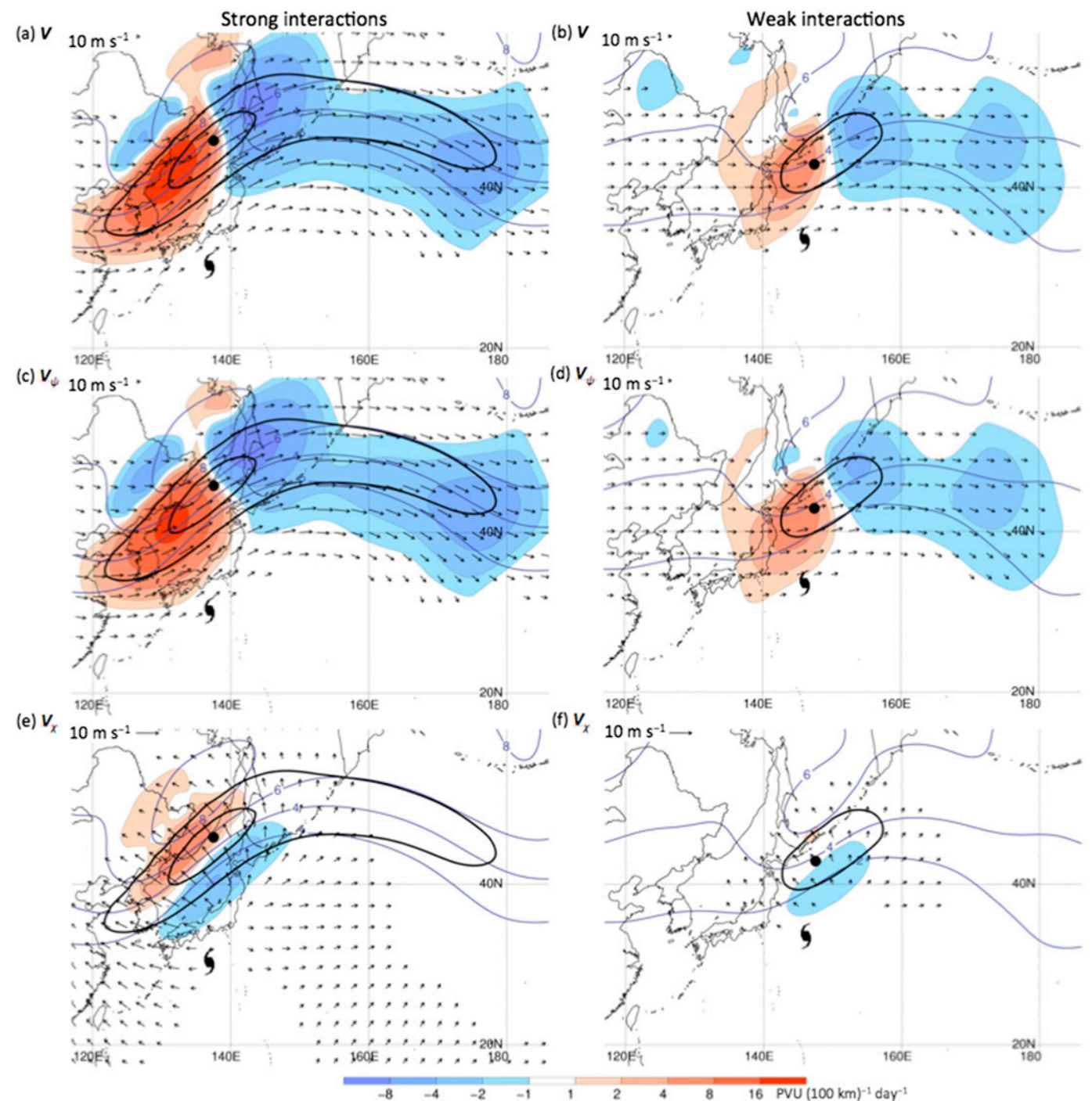

FIG. 12. Interaction-relative composite analyses for (a),(c),(e) strong $(N=54)$ and (b),(d),(f) weak $(N=54)$ TC-extratropical flow interactions at the time of maximum interaction. Analyses show 250-150-hPa layeraveraged PV frontogenesis [shaded, PVU $(100 \mathrm{~km})^{-1}$ day $^{-1}$ ], PV (blue contours, every 2 PVU), PV gradient magnitude [black contours, every $0.5 \mathrm{PVU}(100 \mathrm{~km})^{-1}$ starting at $0.5 \mathrm{PVU}(100 \mathrm{~km})^{-1}$ ], and wind (vectors, $\mathrm{m} \mathrm{s}^{-1}$ ). The black dot denotes the location of the maximum PV gradient magnitude, and the TC symbol denotes the composite TC position. In (a),(b) the total and (c),(d) the nondivergent wind are used to compute PV frontogenesis and are plotted for values $>18 \mathrm{~m} \mathrm{~s}^{-1}$, whereas in (e),(f), the irrotational wind is used to compute PV frontogenesis and is plotted for values $>2 \mathrm{~m} \mathrm{~s}^{-1}$.

system and contributing to its reintensification. The key dynamical role of divergent outflow in facilitating favorable phasing of the TC with the extratropical flow has been noted in case studies of TCs such as WNP TC Dale (Cordeira 2011, 102-112), North Atlantic TC Sandy (2012; Galarneau et al. 2013; Pantillon et al. 2014), and south Indian TC Edisoana (1990; Griffin and Bosart 2014), but has not been previously demonstrated in a composite sense.

Although the downstream extratropical flow response to recurving TCs is found to be highly sensitive to the strength of the TC-extratropical flow interaction, it should be recognized that a strong interaction is not necessarily sufficient to induce a sustained, spatially extensive RWT response. Since equatorward Rossby wave dispersion via anticyclonic wave breaking is hypothesized to be favored where the waveguide/jet stream is weak, terminates abruptly, or exhibits a splitflow pattern, the presence of such flow configurations over the central or eastern North Pacific may limit the downstream flow response to WNP TC recurvature and 


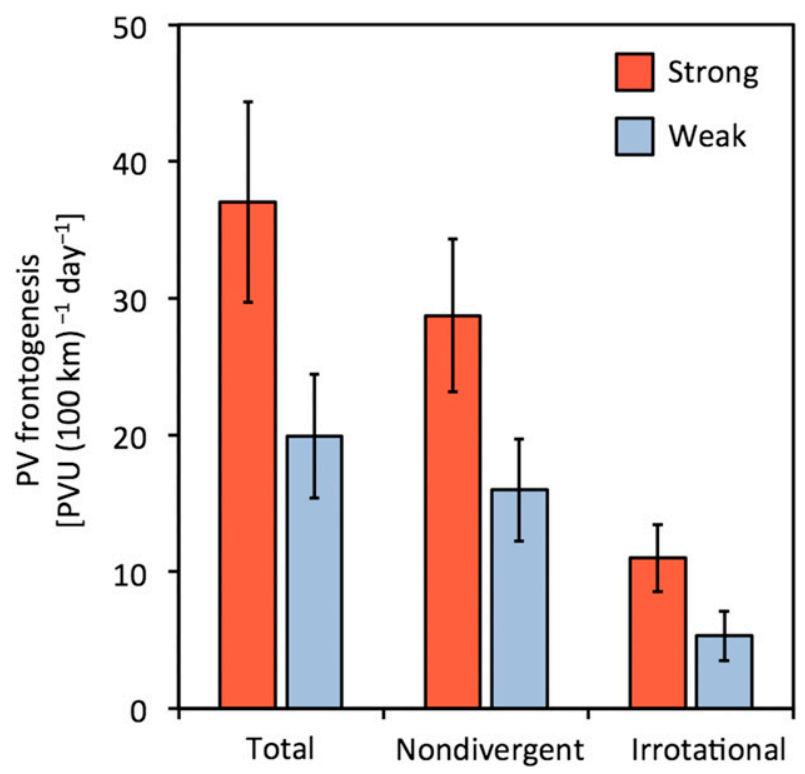

FIG. 13. The means (bars) and standard deviations (whiskers) of the maximum 250-150-hPa layer-averaged PV frontogenesis by the total, nondivergent, and irrotational wind, respectively, for strong $(N=54)$ and weak $(N=54)$ TC-extratropical flow interactions at the time of maximum interaction. The differences between strong and weak interactions for each quantity are significant at the $99.9 \%$ confidence level based on a two-sided Wilcoxon-Mann-Whitney rank-sum test.

therefore limit the potential for a recurving TC to influence the flow pattern over North America.

\section{Summary and future work}

This study uses composite analysis to explore synopticdynamic factors underpinning the statistical relationships between WNP TC recurvature and North Pacific flow amplification documented by Archambault et al. (2013). Composite analyses of all 1979-2009 recurving WNP TCs reveal that, on average, the extratropical flow amplifies over the North Pacific and North America following TC recurvature. This flow amplification is associated with a preexisting RWT migrating from Asia that amplifies over the WNP as the TC recurves and subsequently moves downstream across North America and reaches the Gulf of Mexico. This RWT traverses approximately $240^{\circ}$ of longitude and lasts approximately 10 days.

Composite analyses of strong TC-extratropical flow interactions, objectively defined by the negative PV advection by the irrotational wind associated with the TC, indicate that a preexisting RWT arriving from Asia is amplified by the TC-extratropical flow interaction. The RWT then disperses downstream across the North Pacific to North America. As a result, a high-latitude ridge is established over western North America. The composite analyses of weak TC-extratropical flow interactions indicate the presence of a weak RWT that develops in situ but decays prior to reaching North America.

A comparison of composite analyses of strong and weak TC-extratropical flow interactions at the time of maximum interaction (i.e., the maximum negative PV advection by the irrotational wind associated with the TC) reveals distinct differences between the two types of interactions. Compared with weak interactions, strong interactions feature stronger midlevel forcing for ascent and frontogenesis in a moister environment that is collocated with a region of stronger midlevel warm conveyor beltlike ascent over and northeast of the recurving TC. Additionally, strong interactions tend to feature stronger and broader divergent outflow associated with more pronounced upper-level PV frontogenesis and jet streak intensification.

The findings of this study suggest a variety of avenues for future research. One opportunity is to examine the variability, as opposed to simply the mean, of the observed extratropical flow response to WNP TC recurvature for all recurving TC cases and for strong and weak interaction cases. This analysis could be performed using the clustering technique that Harr et al. (2008) and Anwender et al. (2008) developed to define ensemble forecast scenarios of the extratropical flow during TC recurvature and ET.

The association between recurving WNP TCs and the onset of flow anomalies downstream over North America motivates a comprehensive assessment of whether an increased risk of high-impact weather is present over North America following the recurvature of a WNP TC. For example, the onset of a trough over central North America following WNP TC recurvature indicated by the composite analysis of all recurving WNP TCs suggests a possible connection between recurving TCs and outbreaks of severe convection over the U.S. central plains. Furthermore, the signature of high-latitude ridge amplification in the strong interaction composite indicates a possible link between recurving WNP TCs and high-latitude blocking over western North America.

The signature of an RWT reaching the Gulf of Mexico in the composite analysis of all 1979-2009 recurving WNP TCs indicates that recurving WNP TCs could indirectly influence the behavior of North Atlantic TCs. For example, surrounding the TCextratropical flow interaction of recurving WNP TC Malakas in September 2010 in which an RWT amplified and subsequently traveled downstream to North America (Archambault 2011, p. 158), numerical model forecasts of the downstream flow pattern over the subtropical North Atlantic were characterized by large 
errors, causing National Hurricane Center forecasters difficulty in predicting the genesis, track, and intensity of short-lived Tropical Storm Nicole (J. Beven 2013, personal communication).

Although this study did not directly address predictability, it provides a potential framework in which to evaluate numerical model forecast error and uncertainty associated with the TC-extratropical flow interaction for recurving TC cases and other weather phenomena associated with divergent outflow that may impinge strongly upon the PV waveguide [e.g., predecessor rain events (Bosart et al. 2012; Moore et al. 2013) and atmospheric rivers (Cordeira et al. 2013)]. Many studies suggest that large numerical model forecast errors may result from a failure of the numerical model to adequately capture diabatically driven ridge amplification (e.g., Davies and Didone 2013; Gray et al. 2014), whether associated with recurving TCs (e.g., Henderson et al. 1999; Torn 2010), mesoscale convective systems (e.g., Dickinson et al. 1997; Rodwell et al. 2013), or warm conveyor belts of explosively deepening extratropical cyclones (e.g., Doyle et al. 2014). A question to be addressed is whether forecast error and uncertainty associated with the negative PV advection by the irrotational wind are systematic sources of forecast error and uncertainty in the midlatitudes.

Acknowledgments. We are grateful to the three anonymous reviewers who offered specific, thoughtful suggestions for improvements to an earlier version of the paper. We thank Drs. Brian Colle (Stony Brook University), Christian Grams (ETH), Pat Harr (Naval Postgraduate School), Wayne Higgins (NOAA/Climate Program Office), Michael Riemer (University of Mainz), and Ryan Torn (University at Albany) for helpful discussions. This research was funded by NSF Grants AGS1355960 and AGS-0935830, as well as NOAA Grant NA09OAR4310192. A portion of this research was completed while the first author held a National Research Council Research Associateship Award at the Naval Postgraduate School, and during the first author's threemonth visit with coauthor Chris Davis, which was supported by the NCAR Advanced Study Program Graduate Student Visitor Program.

\section{REFERENCES}

Agustí-Panareda, A., C. D. Thorncroft, G. C. Craig, and S. L. Gray, 2004: The extratropical transition of Hurricane Irene (1999): A potential vorticity perspective. Quart. J. Roy. Meteor. Soc., 130, 1047-1074, doi:10.1256/qj.02.140.

- S. L. Gray, G. C. Craig, and C. Thorncroft, 2005: The extratropical transition of Tropical Cyclone Lili (1996) and its crucial contribution to a moderate extratropical development. Mon. Wea. Rev., 133, 1562-1573, doi:10.1175/MWR2935.1.

Anwender, D., P. A. Harr, and S. C. Jones, 2008: Predictability associated with the downstream impacts of the extratropical transition of tropical cyclones: Case studies. Mon. Wea. Rev., 136, 3226-3247, doi:10.1175/2008MWR2249.1.

— S. C. Jones, M. Leutbecher, and P. A. Harr, 2010: Sensitivity experiments for ensemble forecasts of the extratropical transition of Typhoon Tokage (2004). Quart. J. Roy. Meteor. Soc., 136, 183-200, doi:10.1002/qj.527.

Archambault, H. M., 2011: The downstream extratropical flow response to recurving western North Pacific tropical cyclones. Ph.D. dissertation, University at Albany, State University of New York, 212 pp. [Available online at http://www.atmos. albany.edu/student/heathera/dissertation/.]

, L. F. Bosart, D. Keyser, and A. R. Aiyyer, 2008: Influence of large-scale flow regimes on cool-season precipitation in the northeastern United States. Mon. Wea. Rev., 136, 2945-2963, doi:10.1175/2007MWR2308.1.

,,,--- and J. M. Cordeira, 2013: A climatological analysis of the extratropical flow response to recurving western North Pacific tropical cyclones. Mon. Wea. Rev., 141, 23252346, doi:10.1175/MWR-D-12-00257.1.

Atallah, E. H., and L. F. Bosart, 2003: The extratropical transition and precipitation distribution of Hurricane Floyd (1999). Mon. Wea. Rev., 131, 1063-1081, doi:10.1175/1520-0493(2003)131<1063: TETAPD $>2.0 . \mathrm{CO} ; 2$.

Bosart, L. F., and G. M. Lackmann, 1995: Postlandfall tropical cyclone reintensification in a weakly baroclinic environment: A case study of Hurricane David (September 1979). Mon. Wea. Rev., 123, 3268-3291, doi:10.1175/1520-0493(1995)123<3268: PTCRIA $>2.0 . \mathrm{CO} ; 2$.

—, J. M. Cordeira, T. J. Galarneau Jr., B. J. Moore, and H. M. Archambault, 2012: Predecessor rain events associated with tropical cyclones Ike and Lowell (11-14 September 2008). Mon. Wea. Rev., 140, 1081-1107, doi:10.1175/MWR-D-11-00163.1.

Chaboureau, J.-P., F. Pantillon, D. Lambert, E. Richard, and C. Claud, 2012: Tropical transition of a Mediterranean storm by jet crossing. Quart. J. Roy. Meteor. Soc., 138, 596-611, doi:10.1002/qj.960.

Cordeira, J. M., 2011: Tropical-extratropical interactions and arcticextratropical interactions conducive to intraseasonal variability of the North Pacific jet stream. Ph.D. dissertation, University at Albany, State University of New York, 202 pp. [Available online at http://jasoncordeira.weebly.com/past-research.html.]

, and L. F. Bosart, 2010: The antecedent large-scale conditions of the "Perfect Storms" of late October and early November 1991. Mon. Wea. Rev., 138, 2546-2569, doi:10.1175/ 2010MWR3280.1.

_ , F. M. Ralph, and B. J. Moore, 2013: The development and evolution of two atmospheric rivers in proximity to western North Pacific tropical cyclones in October 2010. Mon. Wea. Rev., 141, 4234-4255, doi:10.1175/MWR-D-13-00019.1.

Danielson, R. E., J. R. Gyakum, and D. N. Straub, 2006: A case study of downstream baroclinic development over the North Pacific Ocean. Part II: Diagnoses of eddy energy and wave activity. Mon. Wea. Rev., 134, 1549-1567, doi:10.1175/MWR3173.1.

Davies, H. C., and A. M. Rossa, 1998: PV frontogenesis and uppertropospheric fronts. Mon. Wea. Rev., 126, 1528-1539, doi:10.1175/1520-0493(1998)126<1528:PFAUTF >2.0.CO;2.

, and M. Didone, 2013: Diagnosis and dynamics of forecast error growth. Mon. Wea. Rev., 141, 2483-2501, doi:10.1175/ MWR-D-12-00242.1. 
Davies-Jones, R., 1991: The frontogenetical forcing of secondary circulations. Part I: The duality and generalization of the Q vector. J. Atmos. Sci., 48, 497-509, doi:10.1175/ 1520-0469(1991)048<0497:TFFOSC > 2.0.CO;2.

Davis, C. A., S. C. Jones, and M. Riemer, 2008: Hurricane vortex dynamics during Atlantic extratropical transition. J. Atmos. Sci., 65, 714-736, doi:10.1175/2007JAS2488.1.

Dickinson, M. J., L. F. Bosart, W. E. Bracken, G. J. Hakim, D. M. Schultz, M. A. Bedrick, and K. R. Tyle, 1997: The March 1993 Superstorm cyclogenesis: Incipient phase synoptic- and convective-scale flow interaction and model performance. Mon. Wea. Rev., 125, 3041-3072, doi:10.1175/1520-0493(1997)125<3041: TMSCIP $>2.0 . C O ; 2$.

Doyle, J. D., C. Amerault, C. A. Reynolds, and P. A. Reinecke, 2014: Initial condition sensitivity and predictability of a severe extratropical cyclone using a moist adjoint. Mon. Wea. Rev., 142, 320-342, doi:10.1175/MWR-D-13-00201.1.

Galarneau, T. J., Jr., C. A. Davis, and M. A. Shapiro, 2013: Intensification of Hurricane Sandy (2012) through extratropical warm core seclusion. Mon. Wea. Rev., 141, 4296-4321, doi:10.1175/MWR-D-13-00181.1.

Grams, C. M., and Coauthors, 2011: The key role of diabatic processes in modifying the upper-tropospheric wave guide: A North Atlantic case study. Quart. J. Roy. Meteor. Soc., 137, 2174-2193, doi:10.1002/qj.891.

- S. C. Jones, C. A. Davis, P. A. Harr, and M. Weissmann, 2013a: The impact of Typhoon Jangmi (2008) on the midlatitude flow. Part I: Upper-level ridgebuilding and modification of the jet. Quart. J. Roy. Meteor. Soc., 139, 2148-2164, doi:10.1002/qj.2091.

,-- , and ——, 2013b: The impact of Typhoon Jangmi (2008) on the midlatitude flow. Part II: Downstream evolution. Quart. J. Roy. Meteor. Soc., 139, 2165-2180, doi:10.1002/qj.2119.

Gray, S. L., C. M. Dunning, J. Methven, G. Masato, and J. M. Chagnon, 2014: Systematic model forecast error in Rossby wave structure. Geophys. Res. Lett., 41, 2979-2987, doi:10.1002/ 2014GL059282.

Griffin, K. S., and L. F. Bosart, 2014: The extratropical transition of Tropical Cyclone Edisoana (1990). Mon. Wea. Rev., 142, 2772-2793, doi:10.1175/MWR-D-13-00282.1.

Hakim, G. J., 2003: Developing wave packets in the North Pacific storm track. Mon. Wea. Rev., 131, 2824-2837, doi:10.1175/ 1520-0493(2003)131<2824:DWPITN>2.0.CO;2.

- 2005: Vertical structure of midlatitude analysis and forecast errors. Mon. Wea. Rev., 133, 567-578, doi:10.1175/MWR-2882.1.

Harr, P. A., and R. L. Elsberry, 2000: Extratropical transition of tropical cyclones over the western North Pacific. Part I: Evolution of structural characteristics during the transition process. Mon. Wea. Rev., 128, 2613-2633, doi:10.1175/ 1520-0493(2000)128<2613:ETOTCO > 2.0.CO;2.

_, and J. M. Dea, 2009: Downstream development associated with the extratropical transition of tropical cyclones over the western North Pacific. Mon. Wea. Rev., 137, 1295-1319, doi:10.1175/2008MWR2558.1.

, and H. M. Archambault, 2015: Dynamics, predictability, and high-impact weather associated with the extratropical transition of tropical cyclones. Dynamics and Predictability of Large-Scale, High-Impact Weather and Climate Events, J. Li et al., Eds., Cambridge University Press, in press.

— , R. L. Elsberry, and T. F. Hogan, 2000: Extratropical transition of tropical cyclones over the western North Pacific. Part II: The impact of midlatitude circulation characteristics. Mon. Wea.
Rev., 128, 2634-2653, doi:10.1175/1520-0493(2000)128<2634: ETOTCO $>2.0 . \mathrm{CO} ; 2$.

- D. Anwender, and S. C. Jones, 2008: Predictability associated with the downstream impacts of the extratropical transition of tropical cyclones: Methodology and a case study of Typhoon Nabi (2005). Mon. Wea. Rev., 136, 3205-3225, doi:10.1175/ 2008MWR2248.1.

Henderson, J. M., G. M. Lackmann, and J. R. Gyakum, 1999: An analysis of Hurricane Opal's forecast track errors using quasi-geostrophic potential vorticity inversion. Mon. Wea. Rev., 127, 292-307, doi:10.1175/1520-0493(1999)127<0292: AAOHOS $>2.0$.CO;2.

Hodyss, D., and E. Hendricks, 2010: The resonant excitation of baroclinic waves by the divergent circulation of recurving tropical cyclones. J. Atmos. Sci., 67, 3600-3616, doi:10.1175/2010JAS3459.1.

Hoskins, B. J., and M. A. Pedder, 1980: The diagnosis of middle latitude synoptic development. Quart. J. Roy. Meteor. Soc., 106, 707-719, doi:10.1002/qj.49710645004.

Jones, S. C., and Coauthors, 2003: The extratropical transition of tropical cyclones: Forecast challenges, current understanding, and future directions. Wea. Forecasting, 18, 1052-1092, doi:10.1175/1520-0434(2003)018<1052:TETOTC >2.0.CO;2.

Kalnay, E., and Coauthors, 1996: The NCEP/NCAR 40-Year Reanalysis Project. Bull. Amer. Meteor. Soc., 77, 437-471, doi:10.1175/1520-0477(1996)077<0437:TNYRP>2.0.CO;2.

Keller, J. H., S. C. Jones, J. L. Evans, and P. A. Harr, 2011: Characteristics of the TIGGE multimodel ensemble prediction system in representing forecast variability associated with extratropical transition. Geophys. Res. Lett., 38, L12802, doi:10.1029/2011GL047275.

$[,-$, and P. A. Harr, 2014: An eddy kinetic energy view of physical and dynamical processes in distinct forecast scenarios for the extratropical transition of two tropical cyclones. Mon. Wea. Rev., 142, 2751-2771, doi:10.1175/MWR-D-13-00219.1.

Kenyon, J. S., 2014: The motion of mesoscale snowbands in northeast U.S. winter storms. M.S. thesis, University at Albany, State University of New York, 108 pp. [Available online at http:// www.atmos.albany.edu/student/jkenyon/Kenyon_thesis.pdf.]

Keyser, D., M. J. Reeder, and R. J. Reed, 1988: A generalization of Petterssen's frontogenesis function and its relation to the forcing of vertical motion. Mon. Wea. Rev., 116, 762-781, doi:10.1175/1520-0493(1988)116<0762:AGOPFF>2.0.CO;2.

_ B. D. Schmidt, and D. G. Duffy, 1992: Quasigeostrophic vertical motions diagnosed from along- and cross-isentrope components of the Q vector. Mon. Wea. Rev., 120, 731-741, doi:10.1175/1520-0493(1992)120<0731:QVMDFA > 2.0.CO;2.

Kistler, R., and Coauthors, 2001: The NCEP-NCAR 50-Year Reanalysis: Monthly means CD-ROM and documentation. Bull. Amer. Meteor. Soc., 82, 247-267, doi:10.1175/ 1520-0477(2001)082<0247:TNNYRM>2.3.CO;2.

Klein, P. M., P. A. Harr, and R. L. Elsberry, 2000: Extratropical transition of western North Pacific tropical cyclones: An overview and conceptual model of the transformation stage. Wea. Forecasting, 15, 373-395, doi:10.1175/1520-0434(2000)015<0373: ETOWNP $>2.0 . \mathrm{CO} ; 2$.

$\ldots, \ldots$, and —_, 2002: Extratropical transition of western North Pacific tropical cyclones: Midlatitude and tropical cyclone contributions to reintensification. Mon. Wea. Rev., 130, 2240-2259, doi:10.1175/1520-0493(2002)130<2240: ETOWNP $>2.0 . \mathrm{CO} ; 2$.

Lang, S. T. K., M. Leutbecher, and S. C. Jones, 2012: Impact of perturbation methods in the ECMWF Ensemble Prediction 
System on tropical cyclone forecasts. Quart. J. Roy. Meteor. Soc., 138, 2030-2046, doi:10.1002/qj.1942.

Martin, J. E., 1999: Quasigeostrophic forcing of ascent in the occluded sector of cyclones and the trowal airstream. Mon. Wea. Rev., 127, 70-88, doi:10.1175/1520-0493(1999)127<0070: QFOAIT $>2.0 . \mathrm{CO} ; 2$.

- 2006: The role of shearwise and transverse quasigeostrophic vertical motions in the midlatitude cyclone life cycle. Mon Wea. Rev., 134, 1174-1193, doi:10.1175/MWR3114.1.

Martius, O., C. Schwierz, and H. C. Davies, 2010: Tropopauselevel waveguides. J. Atmos. Sci., 67, 866-879, doi:10.1175/ 2009JAS2995.1.

McTaggart-Cowan, R., L. F. Bosart, J. R. Gyakum, and E. H. Atallah, 2007: Hurricane Katrina (2005). Part II: Evolution and hemispheric impacts of a diabatically generated warm pool. Mon. Wea. Rev., 135, 3927-3949, doi:10.1175/2007MWR2096.1.

_, G. D. Deane, L. F. Bosart, C. A. Davis, and T. J. Galarneau Jr., 2008: Climatology of tropical cyclogenesis in the North Atlantic (1948-2004). Mon. Wea. Rev., 136, 1284-1304, doi:10.1175/ 2007MWR2245.1.

Miller, J. E., 1948: On the concept of frontogenesis. J. Meteor., 5, 169171, doi:10.1175/1520-0469(1948)005<0169:OTCOF>2.0.CO;2.

Molinari, J., and D. Vollaro, 2012: A subtropical cyclonic gyre associated with interactions of the MJO and the midlatitude jet. Mon Wea. Rev., 140, 343-357, doi:10.1175/MWR-D-11-00049.1.

Moore, B. J., L. F. Bosart, D. Keyser, and M. L. Jurewicz, 2013: Synoptic-scale environments of predecessor rain events occurring east of the Rocky Mountains in association with Atlantic basin tropical cyclones. Mon. Wea. Rev., 141, 1022-1047, doi:10.1175/MWR-D-12-00178.1.

Novak, D. R., L. F. Bosart, D. Keyser, and J. S. Waldstreicher, 2004: An observational study of cold season-banded precipitation in northeast U.S. cyclones. Wea. Forecasting, 19, 993-1010, doi:10.1175/815.1.

Orlanski, I., and J. P. Sheldon, 1995: Stages in the energetics of baroclinic systems. Tellus, 47A, 605-628, doi:10.1034/ j.1600-0870.1995.00108.x.

Pantillon, F., J. P. Chaboureau, C. Lac, and P. Mascart, 2013: On the role of a Rossby wave train during the extratropical transition of Hurricane Helene (2006). Quart. J. Roy. Meteor. Soc., 139, 370-386, doi:10.1002/qj.1974.

— _ - , and E. Richard, 2014: Remote impact of North Atlantic hurricanes on the Mediterranean during episodes of intense rainfall in autumn 2012. Quart. J. Roy. Meteor. Soc., doi:10.1002/qj.2419, in press.

Quinting, J. F., and S. C. Jones, 2014: The impact of tropical cyclones on midlatitude Rossby wave packets: A climatological perspective. 31st Conf. on Hurricanes and Tropical Meteorology, San Diego, CA, Amer. Meteor. Soc., 13C.4. [Available online at https://ams. confex.com/ams/31Hurr/webprogram/Paper244440.html.]
Reynolds, C. A., M. S. Peng, and J. H. Chen, 2009: Recurving tropical cyclones: Singular vector sensitivity and downstream impacts. Mon. Wea. Rev., 137, 1320-1337, doi:10.1175/ 2008MWR2652.1.

Riemer, M., and S. C. Jones, 2010: The downstream impact of tropical cyclones on a developing baroclinic wave in idealized scenarios of extratropical transition. Quart. J. Roy. Meteor. Soc., 136, 617-637, doi:10.1002/qj.605.

$\longrightarrow$, and — 2014: Interaction of a tropical cyclone with a highamplitude, midlatitude wave pattern: Waviness analysis, trough deformation and track bifurcation. Quart. J. Roy. Meteor. Soc., 140, 1362-1376, doi:10.1002/qj.2221.

— - , and C. A. Davis, 2008: The impact of extratropical transition on the downstream flow: An idealized modeling study with a straight jet. Quart. J. Roy. Meteor. Soc., 134, 6991, doi:10.1002/qj.189.

— M. Baumgart, and S. Eiermann, 2014: Cyclogenesis downstream of extratropical transition analyzed by Q-vector partitioning based on flow geometry. J. Atmos. Sci., 71, 4204-4220, doi:10.1175/JAS-D-14-0023.1.

Ritchie, E. A., and R. L. Elsberry, 2007: Simulations of the extratropical transition of tropical cyclones: Phasing between the upper-level trough and tropical cyclone. Mon. Wea. Rev., 135, 862-876, doi:10.1175/MWR3303.1.

Rodwell, M. J., and Coauthors, 2013: Characteristics of occasional poor medium-range weather forecasts for Europe. Bull. Amer. Meteor. Soc., 94, 1393-1405, doi:10.1175/ BAMS-D-12-00099.1.

Saha, S., and Coauthors, 2010: The NCEP Climate Forecast System Reanalysis. Bull. Amer. Meteor. Soc., 91, 1015-1057, doi:10.1175/ 2010BAMS3001.1.

Sardeshmukh, P. D., and B. J. Hoskins, 1988: The generation of global rotational flow by steady idealized tropical divergence. J. Atmos. Sci., 45, 1228-1268, doi:10.1175/1520-0469(1988)045<1228: TGOGRF $>2.0 . \mathrm{CO} ; 2$

Simmons, A. J., and B. J. Hoskins, 1979: The downstream and upstream development of unstable baroclinic waves. J. Atmos. Sci., 36, 1239-1254, doi:10.1175/1520-0469(1979)036<1239: TDAUDO $>2.0 . \mathrm{CO} ; 2$.

Szunyogh, I., Z. Toth, A. V. Zimin, S. J. Majumdar, and A. Persson, 2002: Propagation of the effect of targeted observations: The 2000 Winter Storm Reconnaissance Program. Mon. Wea. Rev., 130, 1144-1165, doi:10.1175/1520-0493(2002)130<1144: POTEOT $>2.0 . \mathrm{CO} ; 2$

Torn, R. D., 2010: Diagnosis of the downstream ridging associated with extratropical transition using short-term ensemble forecasts. J. Atmos. Sci., 67, 817-833, doi:10.1175/ 2009JAS3093.1.

Wilks, D. S., 2006: Statistical Methods in the Atmospheric Sciences. 2nd ed. Academic Press, 627 pp. 